OPEN ACCESS

Edited by:

Piero Crespo,

Spanish National Research Council

(CSIC), Spain

Reviewed by:

Ana Herrero,

Spanish National Research Council

(CSIC), Spain

Matteo Giovarelli,

University of Milan, Italy

*Correspondence: Yu Tian

yu.tian@cmu.edu.cn

Specialty section:

This article was submitted to Signaling,

a section of the journal Frontiers in Cell and Developmental

Biology

Received: 17 October 2021 Accepted: 24 November 2021

Published: 16 December 2021

Citation:

Wu B, Zhang Y, Yu Y, Zhong C, Lang Q, Liang Z, LV C, Xu F and Tian Y (2021) Long Noncoding RNA H19: A Novel Therapeutic Target Emerging in Oncology Via Regulating Oncogenic

Signaling Pathways.

Front. Cell Dev. Biol. 9:796740.

doi: 10.3389/fcell.2021.796740

\section{Long Noncoding RNA H19: A Novel Therapeutic Target Emerging in Oncology Via Regulating Oncogenic Signaling Pathways}

\author{
Baokang Wu ${ }^{1}$, Yizhou Zhang ${ }^{1}$, Yang Yu ${ }^{2}$, Chongli Zhong ${ }^{1}$, Qi Lang ${ }^{1}$, Zhiyun Liang ${ }^{1}$, Chao Lv ${ }^{1}$, \\ Feng $X u^{1}$ and $Y u$ Tian $^{1 *}$
}

${ }^{1}$ Department of General Surgery, Shengjing Hospital of China Medical University, Shenyang, China, ${ }^{2}$ Department of Surgery, Jinzhou Medical University, Jinzhou, China

Long noncoding RNA H19 $(\mathrm{H} 19)$ is an imprinting gene with only maternal expression that is involved in regulating different processes in various types of cells. Previous studies have shown that abnormal $\mathrm{H} 19$ expression is involved in many pathological processes, such as cancer, mainly through sponging miRNAs, interacting with proteins, or regulating epigenetic modifications. Accumulating evidence has shown that several oncogenic signaling pathways lead to carcinogenesis. Recently, the regulatory relationship between $\mathrm{H} 19$ and oncogenic signaling pathways in various types of cancer has been of great interest to many researchers. In this review, we discussed the key roles of $\mathrm{H} 19$ in cancer development and progression via its regulatory function in several oncogenic signaling pathways, such as PI3K/Akt, canonical Wnt/ $\beta$-catenin, canonical NF-kB, MAPK, JAK/STAT and apoptosis. These oncogenic signaling pathways regulated by $\mathrm{H} 19$ are involved in cell proliferation, proliferation, migration and invasion, angiogenesis, and apoptosis of various cancer cells. This review suggests that $\mathrm{H} 19$ may be a novel therapeutic target for cancers treatment by regulating oncogenic signaling pathways.

Keywords: H19, oncogene, signaling pathway, therapeutic target, cancer

\section{INTRODUCTION}

In human genomic, only $2 \%$ of all human genes are protein coding genes, while the $98 \%$ genes are transcribed into non-coding RNA (ncRNA). According to the length of nucleotide sequences, ncRNA can be divided into short ncRNA and long ncRNA (lncRNA). LncRNA with transcript length of $>200$ nucleotides (He et al., 2014). Recently, increasing evidence has uncovered the importance of lncRNA, they could participate in gene expression by regulating epigenetic, transcriptional, and posttranscriptional levels (Charles Richard and Eichhorn, 2018). H19 was the first discovered lncRNA and has a total length of $2.3 \mathrm{~kb}$ (Brannan et al., 1990); it is encoded by a conserved gene cluster H19 locus located on chromosome 11p15.5 in humans and on chromosome seven in mice (Monnier et al., 2013). Similar to mRNAs, H19 has both exons and introns (containing five exons and four introns) (Ghafouri-Fard et al., 2020). H19 is an imprinting gene with only maternal expression. IGF2 is a reciprocally imprinted gene of H19 and only paternal expression, which is located $90 \mathrm{~kb}$ upstream of the H19 gene (Thorvaldsen et al., 1998). Generally, H19 is highly expressed in most tissues of the early stages of embryogenesis or placenta, while significantly declined postnatally, except for several adult tissues, such as skeletal muscle, cartilage, and cardiac muscle 
(Choong et al., 2019; Wang J. et al., 2020). Although, H19 RNA molecules can be detected in the cytoplasm and nucleus, H19 RNA is mainly present in the cytoplasm and functions by regulating RNA or ribosomes (Schoenfelder et al., 2007). Under normal conditions, the expression of $\mathrm{H} 19$ can be regulated by an epigenetic mechanism. When the imprinting control region (ICR) on the paternal chromosome located upstream of $\mathrm{H} 19$ is hypermethylated, which inhibited H19 expression and activated IGF2 expression; while hypomethylation of ICR on the maternal chromosome leads to contrary results. Enhancer regions located downstream of H19 can activate IGF2 expression when the paternal allele ICR region is hypermethylated, while activating H19 expression when the maternal allele ICR region is hypomethylated. Histone deacetylases inhibit H19 expression by interacting with $\mathrm{CpG}$ binding protein two to bind to methylated $\mathrm{CpG}$ dinucleotides (Yang Z. et al., 2021). Additionally, increasing evidence has reported that the expression of $\mathrm{H} 19$ can be regulated by transcription factors, including forkhead Box A1, forkhead Box F2, hypoxia-inducible Factor 1 subunit alpha, paxillin, E2F transcription Factor 1, SRY-sex determining region Y-Box 2, and paternally expressed gene 3 (Berteaux et al., 2005; Marášek et al., 2015; Ye et al., 2016; Wu W. et al., 2017; Zhang J. et al., 2019; Xu et al., 2019; Yang Z. et al., 2021).

H19 plays a key role in regulating different processes in cells. Firstly, H19 functions as a competitive endogenous RNA (ceRNA) (Pope et al., 2017), and ceRNA is referred to as a regulatory network that regulates mRNA expression through "sponging" target miRNA (lncRNA/pseudogene-miRNAmRNA) (Su et al., 2021). MiR-675, one of the targeted miRNAs of H19, is embedded in H19's first exon, and H19 has been shown to inhibit the growth of the placenta before birth by regulating the processing of miR-675. H19 can also interact with other miRNAs, such as miR-326 (Wei et al., 2019), miR-29a (Cheng et al., 2019), miR-124-3p (Liu et al., 2019), miR-152-3p (Zheng et al., 2020), miR-22-3p (Gan et al., 2019), miR-29b-3p (Zhong et al., 2021), miR-193a-3p (Ma et al., 2018), miR-612 (Yu et al., 2020), to regulate biological processes in various types of cells by modulating the expression of downstream target factors, including twist family bHLH transcription factor 1 (TWIST1), thymine DNA glycosylase, integrin $\beta 3$ (ITGB3), bromodomain containing protein 4 (BRD4), Snaill, high mobility group box 1 (HMGB1), presenilin-1 (PSEN1), and Bcl-2. Secondly, H19 is involved in regulating different processes in various types of cells by interacting with different proteins, such as methyl-CpGbinding domain protein 1 (MBD1) (Monnier et al., 2013; Zhang et al., 2017), polypyrimidine tract-binding protein 1 (PTBP1) (Liu et al., 2018), enhancer of zeste homolog 2 (EZH2) (Luo et al., 2013), IGF2 mRNA-binding protein 1 (IGF2BP1) (Runge et al., 2000), p53 (Yang et al., 2012), K homology-type splicing regulatory protein (KSRP) (Giovarelli et al., 2014), zinc finger E-box-binding homeobox 1 (ZEB1) (Song et al., 2017). Thirdly, H19 can participate in epigenetic regulation to regulate gene expression by recruiting epigenetic regulatory factors involved in histone methylation (Alipoor et al., 2020).

Under pathological processes, such as cancer, $\mathrm{H} 19$ can be reexpressed. There is controversy about whether H19 acts as a tumor suppressor gene or oncogenic factor (Gibb et al., 2011). H19 plays differential roles in regulating biological processes in a variety of different types of cancer cells. Abnormal signaling pathways are closely associated with the processes of cancers. In this review, we provide important clues for understanding the key roles of the H19 functional network in signaling pathways and identifying new therapeutic targets for several cancers (Figure 1), such as gastric cancer, hepatocellular carcinoma (HCC), pancreatic cancer, colorectal cancer (CRC), breast cancer, thyroid cancer, non-small cell lung cancer (NSCLC), melanoma, Hodgkin's lymphoma, choriocarcinoma, glioma, bladder cancer, osteosarcoma, multiple myeloma (MM), and oral and cholangiocarcinoma.

\section{ONCOGENIC SIGNALING PATHWAYS REGULATED BY H19 IN CANCER}

\subsection{PI3K/Akt Signaling Pathway}

Increasing evidence has shown the emerging roles of the phosphatidylinositol 3-kinase (PI3K)/Protein kinase B (Akt) signaling pathway in cell proliferation, differentiation, migration, angiogenesis, apoptosis, and other physiological activities (Teng et al., 2021). Under abnormal conditions, this signaling pathway can be overactivated, and PI3K can activate its downstream factor serine/threonine kinase Akt to regulate gene expression. Recently, a large number of studies have reported a positive correlation between $\mathrm{H} 19$ and the PI3K/Akt pathway in various types of cancer, suggesting a promising therapeutic target for cancer treatment.

\section{Gastric Cancer}

According to GLOBOCAN 2018, 1,033,701 new cases and 782,685 deaths occur annually and are associated with gastric cancer, making it the sixth most common cancer and the second most common cause of death by cancer among 36 cancers (Bray et al., 2018), which has caused a significant burden worldwide. H19 is considered an oncogenic lncRNA that activates oncogenic $\mathrm{PI} 3 \mathrm{~K} / \mathrm{Akt}$ signaling in gastric cancer. Based on a new database visualization website of GEPIA with TCGA data and GSE2685 and GSE13861 microarray data from the Gene Expression Omnibus (GEO) databases, H19 is highly expressed in gastric cancer tissue samples. From data from The Cancer Genome Atlas (TCGA) databases, high $\mathrm{H} 19$ expression gastric cancer patients had a shorter overall survival. Likewise, gastric cancer patients with high $\mathrm{H} 19$ expression had a shorter recurrence-free survival in GSE26253 microarray data from GEO databases. Both these suggest that H19 could be a prognostic value lncRNA in gastric cancer. Additionally, studies showed the same results. Researchers examined $\mathrm{H} 19$ expression levels at the in vitro cell level and found that $\mathrm{H} 19$ was upregulated in the gastric cancer cell lines AGS, MKN-45, and SGC-7901 compared with the normal gastric mucosa cell line GES-1. Moreover, researchers examined H19 expression levels in 12 pairs of fresh gastric cancer tissues and corresponding normal adjacent tissues, and the RT-qPCR results indicated that $\mathrm{H} 19$ was more highly expressed in gastric cancer tissues than in corresponding normal adjacent tissues (Sun 


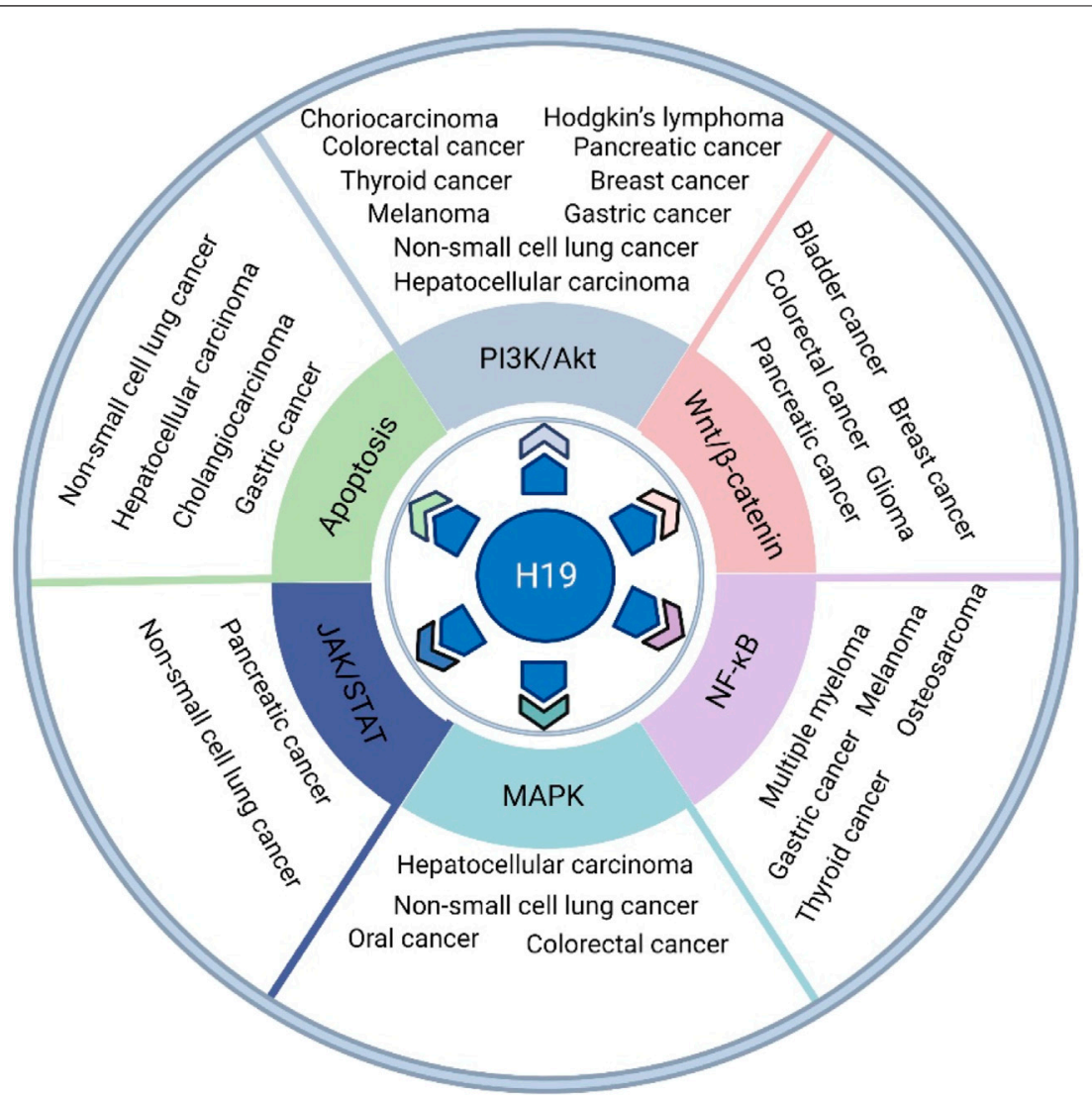

FIGURE 1 The role of H19 in various types of cancer, such as gastric cancer, HCC, pancreatic cancer, CRC, breast cancer, thyroid cancer, NSCLC, melanoma, Hodgkin's lymphoma, choriocarcinoma, glioma, bladder cancer, osteosarcoma, multiple myeloma, oral cancer and cholangiocarcinoma, via its regulatory function in several oncogenic signaling pathways, such as the PI3K/Akt, canonical Wnt/ $\beta$-catenin, canonical NF-kB, MAPK, JAK/STAT and apoptosis pathways.

et al., 2021). H19 positively correlates with miR-675 expression in gastric cancer. Runt domain transcription Factor 1 (RUNX1), an important tumor suppressor, is an important downstream molecule of the H19/miR-675 axis, and both H19 and miR675 decrease RUNX1 expression. In AGS cells, the H19/miR-675 axis could enhance the activation of AKT/mTOR signaling by promoting the phosphorylation of Akt and mTOR (Liu et al., 2016). In AGS cells cotransfected with the RUNX1 overexpression plasmid and miR-675 mimic, overexpression of RUNX1 inhibited miR-675 mimic-induced Akt and mTOR miR675 mimic phosphorylation. Taken together, these data demonstrated that H19-derived miR-675 regulated gastric cancer cell progression due to its ability to activate the Akt/ mTOR pathway by inhibiting the downregulation of RUNX1 (Liu et al., 2016).

\section{Hepatocellular Carcinoma}

Liver cancer was the seventh most common malignancy $(841,080$ new cases, $4.7 \%$ of the total) and the third leading cause of cancerrelated death among 36 cancers $(781,631$ deaths, $8.2 \%$ of the total) in 2018 (Bray et al., 2018). It is universally acknowledged that the pathogenesis of HCC is complex, genomics mechanisms play a vital role. To ease this burden, the genomics mechanisms of HCC need to be investigated. H19 has been observed to modulate the PI3K/Akt signaling pathway in HCC. In the HCC cell lines of Huh-7, MHCC-97H and HepG2, the relative RNA levels of both H19 and miR-675 detected by qRT-PCR were higher than those in normal human hepatic LO2 cells. After treatment with a miR675 inhibitor and H19 siRNA, the qRT-PCR results showed that H19 and miR-675 levels were decreased, which enhanced the migration and invasion of HCC, accompanied by dramatically increased expression levels of Akt and Cdc25A and decreased expression levels of glycogen synthase kinase $3 \beta$ (GSK-3 $\beta$ ) (Lv et al., 2014). Taken together, these data demonstrated that downregulation of $\mathrm{H} 19$ and miR-675 expression can promote the migration and invasion of HCC cells via the Akt/GSK-3 $\beta$ / Cdc25A signaling pathway.

\section{Pancreatic Cancer}

Pancreatic cancer is one of the leading causes of human cancerrelated death worldwide with increasing incidence, and there are more than 458,918 new cases and 432,242 deaths annually (Bray et al., 2018). It is very malignant with a high mortality rate due to the lack of specific therapies, and its pathogenesis remains unclear. Recently, H19 was determined to be a promising therapeutic target for pancreatic cancer. In an established nude 
mouse xenograft model using T3M4, PANC-1, COLO357 and CAPAN-1 cells with a siH19 mixture or lenti-H19-GFP, H19 overexpression could increase tumor volume and weight and promote tumor growth quickly, while H19 knockout exerted the opposite consequence (Ma et al., 2016). Neurosecretory protein (VGF) is a highly conserved inducible gene for neurotrophic factors and is associated with pancreatic neuroendocrine functions. H19 regulated the VGF expression level, which promoted pancreatic neuroendocrine neoplasm cell proliferation, migration and invasion. In QGP-1 cells, western blotting results showed that $\mathrm{H} 19$ could activate VGF-mediated phosphorylation of PI3K, Akt, and cAMP-response element binding protein (CREB). In the xenografted tumors, western blotting analysis identified similar results. In summary, these results demonstrated that $\mathrm{H} 19$ could promote pancreatic neuroendocrine neoplasm progression via the VGF-mediated PI3K/Akt/CREB pathway (Ji et al., 2019).

\section{Colorectal Cancer}

CRC ranks as the fourth most common malignancy $(1,096,601$ new cases, $6.1 \%$ of the total) in the world and was the fifth leading cause of cancer-related death (551.269 deaths, 5.8\% of the total) in 2018 (Bray et al., 2018). The molecular pathogenesis mechanism of CRC is complex. A recent study focused on H19 playing a vital regulatory function in the progression of CRC via the PI3K/Akt signaling pathway, which provides a promising method for improving early diagnosis, predicting prognosis, and developing effective therapies. Researchers investigated the RNA expression data of CRC patients obtained from 622 CRC cancer tissues and 51 adjacent nontumor normal tissues from the TCGA data portal, and the results showed that $\mathrm{H} 19$ is highly expressed in human CRC tissues (Zhong et al., 2019). As mentioned above, H19 functions as a ceRNA to modulate the various processes of cells. Zhong and others constructed the ceRNA network of CRC using 10 lncRNAs, 5 pseudogenes, 122 mRNAs, and 39 miRNAs and found that $\mathrm{H} 19$ could sponge to target 6 miRNAs and interact with 38 mRNAs in this ceRNA; These CRC-related mRNAs participate in the PI3K/Akt signaling pathway. Western blot analysis revealed that $\mathrm{H} 19$ knockdown suppressed the expression of MET, ZEB1, and collagen type I alpha 1 (COL1A1) in the H19 ceRNA network mentioned above in both HT-29 and HCT116 cells. Additionally, overexpression of $\mathrm{H} 19$ is associated with poor prognosis and clinical parameters such as tumor grade, lymphatic invasion, metastasis, and TNM stage (Zhong et al., 2019).

\section{Breast Cancer}

Breast cancer is a globally observed malignancy $(2,088,849$ new cases, $11.6 \%$ of the total) and is the fourth leading cause of cancerrelated death $(626,679$ deaths, $5.8 \%$ of the total) worldwide (Bray et al., 2018). Chemotherapeutics have been widely used for breast cancer treatment, either as single agents or in combination with other chemotherapeutic agents; however, the emergence of chemotherapeutic resistance has become a huge obstacle for breast cancer treatment (Du et al., 2021). Previous studies have shown that $\mathrm{H} 19$ is associated with the pathogenesis of breast cancer. Compared to healthy tissues, H19 is upregulated in approximately $73 \%$ of breast cancer tissues. Interestingly, a recent study demonstrated that $\mathrm{H} 19$ is associated with chemotherapeutic resistance in breast cancer via the PI3K/Akt signaling pathway (Han et al., 2018). Triple-negative breast cancer (TNBC), one of the subtypes of breast cancer, has a high metastatic capability and poor prognosis when compared to other subtypes (Guney Eskiler et al., 2018). Recently, Han and others found that $\mathrm{H} 19$ is significantly overexpressed and induces paclitaxel resistance in TNBC cell lines. Furthermore, H19 knockout rescued paclitaxel resistance in the TNBC cell line by decreasing the expression of phosphorylated Akt (Ser473) and $\mathrm{Bcl}-2$ and increasing the expression of Bax and cleaved caspase-3. These data demonstrated that H19 knockout rescued paclitaxel resistance in TNBC via the Akt-mediated apoptotic signaling pathway (Han et al., 2018). Additionally, established xenograft nude mice using MDA-MB-231/PTXshH19 cells and MDA-MB-231/PTX-shNC cells showed the same results as above.

\section{Thyroid Cancer}

Thyroid cancer has a lower malignancy than the above cancers, ranking ninth in incidence $(567,233$ new cases) with a lower leading cause of cancer-related death (41,071 deaths). However, the incidence of thyroid cancer has been increasing in many countries since the early 1980s and is approximately 3 times higher in women than men (Bray et al., 2018). It is necessary to understand its pathogenesis for effective prevention, early diagnosis, and better prognosis. $\mathrm{H} 19$ is involved in the expression of members of the PI3K/Akt signaling pathway to regulate thyroid cancer progression. $\mathrm{H} 19$ is over six-fold overexpressed in thyroid cancer tissues compared with adjacent normal tissues. H19 knockout inhibited cell viability and induced apoptosis of thyroid cancer cells by prominently increasing the expression of Bax and caspase three and repressing the expression of Bcl-2. Moreover, the authors found that the $\mathrm{PI} 3 \mathrm{~K} /$ Akt signaling pathway is involved in the process by which H19 silencing inhibits thyroid cancer cell viability and induces apoptosis with significantly decreased phosphorylated PI3K and phosphorylated Akt (Li et al., 2019).

\section{Non-Small Cell Lung Cancer}

Global statistics in 2018 showed that lung cancer is the most common cancer among malignant tumors, and its morbidity and mortality are the highest in males and third most common form of cancer and second most common cause of cancer-related death in females (Bray et al., 2018). NSCLC accounts for a high proportion of lung cancer cases. Epidermal growth factor receptor (EGFR) tyrosine kinase inhibitors, such as erlotinib, have been proven to benefit NSCLC by inhibiting the activation of EGFR gene mutations (Paez et al., 2004). However, drug resistance appears after approximately 12 months of drug use, which is a major challenge for cancer treatment. Increasing evidence has demonstrated that $\mathrm{H} 19$ is associated with drug resistance in lung cancer by modulating the PI3K/Akt signaling pathway. Chen and others found that $\mathrm{H} 19$ is downregulated in erlotinib-resistant EGFR mutant human 
NSCLC cell lines HCC827 and PC9. H19 downregulation confers erlotinib resistance. Moreover, H19 knockdown reduces the inhibitory effect of erlotinib on the phosphorylation of Akt. Increased AKT activation leads to erlotinib resistance in NSCLC. Researchers have also confirmed the above results in xenograft tumors (Chen et al., 2020).

\section{Melanoma}

Melanoma is a lethal form of skin cancer that originates from cells containing pigment (Hodis et al., 2012). The incidence of melanoma has continued to increase worldwide, and there were 287,723 new cases and 60,712 deaths in 2018 (Bray et al., 2018). The 5-years survival rate is very low when metastasis occurs. Recently, studies have demonstrated that the level of H19 expression is correlated with the migration and invasion of melanoma cells by regulating the activation of the PI3K/Akt signaling pathway (Zhu et al., 2018; Bi et al., 2019). Zhu and colleagues showed that $\mathrm{H} 19$ promotes the proliferation, invasion, and growth of melanoma cell line A375 by upregulating Akt phosphorylation, increasing the expression of matrix metalloproteinases 2 (MMP2), MMP9, and Slug and downregulating the expression of E-cadherin (Zhu et al., 2018). Schizandrin A (SchA), a novel antioxidant compound, has been proven to exert antitumor properties in melanoma. $\mathrm{Bi}$ and colleagues demonstrated that SchA is negatively correlated with the level of H19. SchA inhibited cell proliferation and migration and increased cell apoptosis in the melanoma cell line A375 by downregulating the expression of H19, which in turn inactivated the PI3K/Akt signaling pathway by decreasing the phosphorylation of PI3K and Akt. Furthermore, H19 overexpression exerted the opposite results (Bi et al., 2019). Therefore, H19 is a potential target for the treatment of melanoma.

\section{Hodgkin's Lymphoma}

Hodgkin's lymphoma is a lymphoid hematopoietic system malignant tumor with a gradually increasing incidence. In 2018, 287,723 new cases and 60,712 deaths occurred worldwide (Bray et al., 2018). Its pathogenesis is complex, and we need to further explore the potential mechanism of Hodgkin's lymphoma. Recently, H19 was reported to be involved in the pathogenesis of Hodgkin's lymphoma via the PI3K/Akt signaling pathway, which provides a novel strategy for this cancer treatment by regulating the expression of H19. Wang and colleagues detected tissues from 60 Hodgkin's lymphoma patients and 40 reactive hyperplasia of lymph nodes. qRT-PCR results showed that H19 is significantly overexpressed in Hodgkin's lymphoma tissues compared to reactive hyperplasia of lymph nodes. More importantly, overexpression of H19 promoted Hodgkin's lymphoma cell proliferation by regulating Akt expression, while H19 knockout exerted the opposite results (Wang Y. et al., 2019).

\section{Choriocarcinoma}

Choriocarcinoma is a highly malignant trophoblastic cell tumor (Bazot et al., 2004). Although the incidence is relatively low, it easily metastasizes and has a poor prognosis. Thus far, chemotherapy has been the major treatment. It is necessary for us to understand the molecular mechanisms of choriocarcinoma to inhibit metastatic ability. H19 has been proven to be involved in the development of the human choriocarcinoma cell line JAR by acting on the PI3K/Akt signaling pathway. Yu and colleagues showed that H19 is related to the drug resistance mechanism of choriocarcinoma. H19 is significantly overexpressed in the methotrexate- and 5fluorouracil-resistant human choriocarcinoma cell line JEG-3. H19 knockout inhibited the proliferation, migration and invasion and promoted the apoptosis of choriocarcinoma-resistant cells. More importantly, the authors also found that the PI3K/Akt/ mechanistic target of rapamycin (mTOR) signaling pathway might be involved in H19-mediated effects. Western blot analysis showed that the levels of phosphorylated PI3K, Akt, and mTOR were dramatically increased in H19 knockout methotrexate- and 5-fluorouracil-resistant JEG-3 cells. Interestingly, after inhibition of phosphorylated PI3K/Akt/ mTOR, the effects mediated by H19 were markedly reversed (Yu et al., 2019).

\subsection{Canonical Wnt/ $\beta$-Catenin Signaling Pathway}

Increasing evidence has demonstrated that Wnt signaling pathways are involved in diverse physiological processes. Because Wnt proteins interact with the downstream factor $\beta$-catenin in the cascade reaction, the Wnt signaling pathways can be divided into two subpathways: canonical Wnt/ $\beta$-catenin signaling and noncanonical $\mathrm{Wnt} / \mathrm{PCP}$ and $\mathrm{Wnt} / \mathrm{Ca}^{2+}$ signaling (Xu et al., 2020). At present, the canonical Wnt $/ \beta$-catenin signaling pathway is the best-characterized pathway, and studies have shown that abnormal Wnt $/ \beta$-catenin signaling contributes to the pathogenesis of various cancers (Zhang and Wang, 2020). Under pathogenic conditions, Wnt/ $\beta$-catenin signaling is abnormally activated by the binding of Wnt ligands to the low-density lipoprotein receptor-related proteins 5/6 (LRP5/6) receptor and Frizzled receptor. Subsequently, the Frizzled receptor recruited disheveled (DVL), leading to LRP5/6 phosphorylation and the recruitment of Axin (Bilic et al., 2007). Furthermore, activated disheveled (DVL) inhibited the degradation of $\beta$-catenin mediated by GSK- $3 \beta$ and casein kinase $1 \alpha$ (CK1 $\alpha)$ destruction complex, leading to an elevation of $\beta$-catenin levels in the cytoplasm. Elevation of cytosolic $\beta$-catenin could translocate into the nucleus to regulate Wnt target gene expression by interacting with either p300 or CREB-binding protein as a transcriptional coactivator for $\mathrm{T}$ cell-specific factor (TCF)/lymphoid enhancerbinding factor (LEF) (Bilic et al., 2007; Hu et al., 2020). Recently, increasing evidence has indicated that $\mathrm{H} 19$ expression is significantly associated with abnormal $\mathrm{Wnt} / \beta$-catenin signaling pathways in various types of human cancers, such as pancreatic cancer, CRC, glioma, breast cancer, and bladder cancer. The molecular mechanisms are complex and are described in detail below.

\section{Pancreatic Cancer}

Abnormal expression of $\mathrm{H} 19$ and its downstream factors has been observed in pancreatic cancer by regulating the $\mathrm{Wnt} / \beta$-catenin 
signaling pathway (Sun et al., 2019). PFTK1 (cyclin-dependent kinase 14, CDK14) mediates the phosphorylation of LRP5/6 involved in the Wnt/ $\beta$-catenin pathway (Davidson et al., 2009). In 45 paired pancreatic ductal adenocarcinoma and noncancerous tissue samples, both H19 and PFTK1 were highly expressed and correlated with distant metastasis, advanced TNM stages, and overall survival. MiR-194 has been found to directly bind to upstream H19 and target downstream PFTK1 by directly binding to the $3^{\prime}$-untranslated region $\left(3^{\prime}\right.$ UTR). This H19/miR-194/PFTK1 axis modulated pancreatic ductal adenocarcinoma cell proliferation and migration through $\mathrm{Wnt} / \beta$-catenin signaling by regulating the levels of phosphorylated LRP6 Snail and increasing phosphorylated $\beta$-catenin protein levels (Sun et al., 2019).

\section{Colorectal Cancer}

In CRC, H19 was found to be abnormally expressed and associated with the abnormally activated Wnt/ $\beta$-catenin signaling pathway (Wu K.-f. et al., 2017; Ding D. et al., 2018). According to the TCGA database, H19 was significantly highly expressed in CRC tissues in comparison to normal tissues, while miR-29b-3p was significantly downregulated in the collected CRC tissues compared with adjacent normal tissues. Consistent with TCGA data, the same results were found in CRC patients and cell lines. H19 directly targeted miR-29b-3p to inhibit its expression. Moreover, miR-29b-3p directly targets downstream progranulin to participate in the activation of the $\mathrm{Wnt} / \beta$-catenin signaling pathway, causing apparent alterations in the epithelial mesenchymal transition (EMT) process and remarkably different transcriptional activities of the $\beta$-catenin/ $\mathrm{T}$ cell-specific factor (TCF) reporter plasmid (Ding D. et al., 2018). In summary, the H19/miR-29b-3p/progranulin axis is involved in the EMT process of CRC by regulating the Wnt/ $\beta$-catenin signaling pathway. Additionally, H19 mediated drug resistance in CRC by regulating the $\mathrm{Wnt} / \beta$-catenin signaling pathway. In the methotrexate-resistant colorectal cell line HT29 (HT-29-R), H19 was significantly upregulated. H19 knockdown could restore the sensitivity of HT-29-R cells to methotrexate resistance through the $\mathrm{Wnt} / \beta$-catenin signaling pathway by inhibiting the expression of $\beta$-catenin (Wu K.-f. et al., 2017).

\section{Breast Cancer}

H19 could regulate breast cancer cell processes by acting on the $\mathrm{Wnt} / \beta$-catenin signaling pathway. In the paclitaxel-resistant (PR) cell subline (MCF-7/PR), H19 was upregulated, and could as a ceRNA via competitively binding miR-340-3p, which regulates cell proliferation, migration, invasion and apoptosis (Yan et al., 2020). YWHAZ (tyrosine 3-monooxygenase/tryptophan 5monooxygenase activation protein zeta) is a direct downstream target of miR-340-3p, H19 regulates the breast cell progression miR-340-3p/YWHAZ axis, and the H19/miR340-3p/YWHAZ axis altered EMT phenotype in breast cancer metastasis and invasion by regulating $\beta$-catenin expression, accompanied with changed expression of E-cadherin, Slug, Snail, Vimentin, Cyclin D1, and c-Myc (Yan et al., 2020). Breast cancer stem-like cells (BrCSCs) have a strong self- renewal ability and are considered the greatest obstacle for breast cancer treatment. H19 stimulated the symmetric division of BrCSCs. Let-7c is a protective indicator, and Wnt signaling is excessively activated in breast cancer. H19, as a ceRNA, inhibits Let-7c expression through the estrogen receptor $1 / \mathrm{Wnt}$ cycle to induce BrCSC symmetric division (Wang M. et al., 2019).

\section{Glioma}

Glioma is a common and highly malignant tumor of the central nervous system with a poor prognosis, which is not sensitive to radiotherapy and chemotherapy. As far, the pathogenesis of glioma is complex and unclear (Deangelis, 2001). Hence, identifying molecular targets for the diagnosis and treatment of gliomas is important. Increasing evidence had shown that H19 regulated the development of glioma by regulating the Wnt/ $\beta$-catenin signaling pathway (Guan et al., 2019; Zhou et al., 2020). H19 expression was higher in glioma tissues and cell lines with a poor prognosis. H19 knockdown inhibited glioma cell proliferation, invasion, and migration, arrested the glioma cell cycle and induced glioma cell apoptosis. H19 modulated the above glioma cell processes by regulating the activation of the Wnt/ $\beta$-catenin signaling pathway (Guan et al., 2019). As mentioned above, H19 functions as a ceRNA to regulate cell processes. H19 had been found to directly target miR-342, decreasing its expression. Consistent with the above results, H19 was highly expressed in glioma and directly targets miR342 to regulate $\mathrm{Wnt} 5 \mathrm{a} / \beta$-Catenin to modulate cell proliferation, migration, and angiogenesis. H19 silencing reversed glioma cell growth and metastasis by regulating the miR-342-mediated Wnt5a/ $\beta$-Catenin signaling pathway with decreased levels of vascular endothelial growth factor A (VEGFA), MMP9, Wnt5a, and $\beta$-catenin (Zhou et al., 2020).

\section{Bladder Cancer}

According to GLOBOCAN 2018, over 549,000 new bladder cancer cases and 200,000 deaths were estimated globally (Bray et al., 2018). Given its aggressiveness, it is considered the major obstacle for bladder cancer treatment, and patients with aggressive bladder cancer often have a poor prognosis with a 50\% 5-years survival (Kim et al., 2010). A recent study demonstrated that H19 plays a vital role in bladder cancer invasion and metastasis (Luo et al., 2013). H19 is significantly upregulated in most bladder cancer tissues and invasive bladder cancer cell lines. EZH2, as a critical component of polycomb repressive complex 2 (PRC2), is associated with cancer metastasis (Wang et al., 2013). Luo and colleagues found that H19 is associated with EZH2, which increases the activation of the $\mathrm{Wnt} / \beta$-catenin signaling pathway, resulting in decreased expression of E-cad. Taken together, these data demonstrated that the association of $\mathrm{H} 19$ upregulation with EZH2 increased bladder cancer metastasis by inhibiting Wnt $/ \beta$-catenin-mediated E-cad expression (Luo et al., 2013).

\subsection{Canonical NF-кB Signaling Pathway}

The canonical nuclear factor kappa $B(N F-\kappa B)$ signaling pathway, one of the NF- $\mathrm{BB}$ pathways, plays an important role in multiple 
physiological and pathological processes. It is well established that the pathway can be activated by various cytokines, such as tumor necrosis factor alpha (TNF- $\alpha$ ), interleukin-1 (IL-1), and lipopolysaccharides (LPS) (Hoesel and Schmid, 2013; Taniguchi and Karin, 2018). The engagement of these cytokines with their receptor initially activates the downstream cascade molecule $\mathrm{I} \kappa \mathrm{K}$

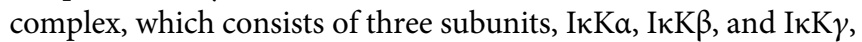
resulting in the phosphorylation of $\mathrm{I} \kappa \mathrm{B} \alpha$ at S32 and S36 and subsequent ubiquitination and proteasomal degradation. p50/p65 dimers released from the I $\mathrm{B} \mathrm{B} \alpha / \mathrm{p} 50 / \mathrm{p} 65$ complex after the degradation of $\mathrm{I} \kappa \mathrm{Ba}$ translocate to the nucleus to regulate the expression of inflammation- and immune-related genes (Hoesel and Schmid, 2013). Increasing studies have demonstrated that $\mathrm{H} 19$ regulates canonical NF- $\mathrm{kB}$ signaling pathway activation in various types of human cancers, such as gastric cancer, thyroid cancer, melanoma, osteosarcoma, and multiple myeloma.

\section{Gastric Cancer}

$\mathrm{H} 19$ has been reported to be associated with altered expression of the components of the canonical NF- $\kappa \mathrm{B}$ signaling pathway in gastric cancer. In Helicobacter pylori (HP)-infected gastric cancer tissues and cells, H19 is noteworthily highly expressed. Additionally, HP infection promotes gastric cancer cell viability, migration, invasion and the inflammatory response. $\mathrm{HP}$ infection promotes I $\mathrm{B} \mathrm{B}$ ubiquitination and proteasomal degradation and p65 translocation, and this ability is enhanced by overexpression of H19. H19 overexpression promotes HPinduced gastric cancer cell proliferation, migration, and invasion by altering the expression of $I \kappa B a$, phosphorylated $I \kappa B a$ and p65 in the canonical NF- $\kappa B$ signaling pathway (Zhang Y. et al., 2019).

\section{Thyroid Cancer}

In thyroid cancer, H19 may be a suppressor gene, and its overexpression inhibits cell viability, migration, and invasion but promotes cell apoptosis. Meanwhile, H19 knockdown has demonstrated contrary results. Furthermore, H19 overexpression negatively regulates insulin receptor substrate I expression to modulate the above processes in SW579 and TPC1 thyroid cancer cells. Decreased insulin receptor substrate I regulates the PI3K/ Akt signaling pathway and NF-kB signaling pathway by decreasing the levels of phosphorylated PI3K, phosphorylated Akt, phosphorylated p65, and phosphorylated IKBa in SW579 and TPC-1 thyroid cancer cells (Wang et al., 2017).

\section{Melanoma}

Likewise, H19 exerts an important role in melanoma by regulating the NF-kB signaling pathway. H19 is significantly more highly expressed in melanoma tumor tissue than in adjacent healthy tissue. Moreover, H19 knockdown inhibits melanoma cell proliferation, migration and invasion. H19 knockdown decreases the levels of p65 and p50 to inhibit the activation of the NF- $\kappa B$ signaling pathway by inactivating the PI3K/Akt signaling pathway (Liao et al., 2018). These data showed that H19 regulates melanoma cell processes by inactivating the PI3K/Akt-mediated NF- $\kappa \mathrm{B}$ signaling pathway.

\section{Osteosarcoma}

Osteosarcoma is a relatively rare type of cancer; however, similar to other cancers, its pathogenesis is complex and certainly places a burden on children and young adults (Botter et al., 2014). Increasing evidence has shown that the H19 is involved in the development of osteosarcoma, and the mechanisms are more complex and need further investigation. H19 regulates osteosarcoma cell processes by acting on the NF- $\kappa \mathrm{B}$ signaling pathway, and as one of the mechanisms, H19 has been investigated (Zhao and Ma, 2018). H19 was significantly overexpressed in osteosarcoma tumor tissue compared with adjacent healthy tissue. Moreover, H19 has been associated with distant metastasis of osteosarcoma and overall survival of patients with osteosarcoma. Osteosarcoma cell migration and invasion have been significantly reduced by H19 knockdown, which may be associated with inactivation of the NF- $\kappa B$ signaling pathway. H19 knockdown apparently increases the level of I $\mathrm{Ba}$ by regulating the activation of the PI3K/Akt signaling pathway in osteosarcoma cell lines compared with normal cells (Zhao and Ma, 2018).

\section{Multiple Myeloma}

$\mathrm{MM}$ is a bone marrow-resident hematological malignancy of plasma cells and is responsible for 159,985 cases worldwide (Bray et al., 2018; Minnie and Hill, 2020). Although the 5-years overall survival rate of $\mathrm{MM}$ has increased in recent decades, the incidence of MM has increased uniformly since 1990 (Cowan et al., 2018). Based on the increased incidence, it is urgent to well characterize the molecular mechanisms for effective and better treatment of MM. Recently, H19, as a cancer-promotive gene in MM that acts on the NF- $\mathrm{BB}$ signaling pathway, was investigated (Sun et al., 2017). H19 significantly overexpressed MM tissues and cells and was associated with a worse prognosis in patients with MM. Moreover, H19 knockdown inhibited the activation of the NF- $\mathrm{B}$ signaling pathway by reducing the levels of phosphorylated I $\kappa \mathrm{B} \alpha$ and nuclear P65 to modulate MM cell growth. Additionally, a positive correlation between $\mathrm{H} 19$ and the levels of the cytokines IL-6 and IL-8 was observed in MM (Sun et al., 2017).

\subsection{MAPK Signaling Pathway}

The mitogen-activated protein kinase (MAPK) signaling pathways have been proven to regulate various cell processes and play an important role in carcinogenesis. There are three main classical MAPK subgroup pathways: extracellular regulated protein kinases (ERK)/MAPKs, c-Jun N-terminal kinase (JNK)/ MAPKs, and p38/MAPKs (Peluso et al., 2019). Under pathogenic conditions, all three subgroup pathways are involved in carcinogenesis. In the ERK/MAPK pathway, the first line of cytosolic intermediate Ras is activated after growth factors engage with their receptors; subsequently, activated Ras activates the downstream Raf/MEK/ERK kinase cascade to inhibit cell apoptosis (Braicu et al., 2019). The JNK/MAPK and p38/MAPK pathways are activated by various stress stimuli to promote apoptosis. After various stress stimuli, the MKK/JNK kinase cascade and MKK/p38 kinase cascade are activated (Zeke et al., 2016; Anton et al., 2021). Among 
cancers, such as liver cancer, colon cancer, non-small cell lung cancer, and oral cancer, $\mathrm{H} 19$ is associated with the progression of these cancers by altering the level of the component of the MAPK signaling pathway.

\section{Hepatocellular Carcinoma}

$\mathrm{H} 19$ is overexpressed and results in a poor clinical outcome in patients with HCC. Of note, H19 overexpression is slightly associated with large tumors and portal vein tumor thrombi. H19 could regulate migration and invasion by inducing EMT in HepG2 cells. Furthermore, H19 functions as a ceRNA to hijack miR-193b and protect ERK2. The ceRNA network of H19/miR193b/MAPK1 is abnormally activated in HCC, leading to the activation of the MAPK signaling pathway, which promotes aggressiveness in HCC (Ye et al., 2020). Similar to the above results, H19 is highly expressed in CD133 + HCC stem cells, and H19 overexpression activates the MAPK signaling pathway by increasing the levels of phosphorylated MAPK and phosphorylated ERK1/2. Additionally, H19 has a dramatic effect on oxidative stress. H19 knockdown also causes a significant enrichment of reactive oxygen species in CD133+ HCC stem cells (Ding K. et al., 2018).

\section{Colorectal Cancer}

As mentioned above, $\mathrm{H} 19$ promotes the migration and invasion of CRC cells by regulating PI3K/Akt. Recently, a study also investigated whether H19 may promote metastasis and invasion in CRC by activating the Ras/ERK signaling pathway. H19 could regulate the activation of RAS and subsequently affect the levels of phosphorylated Raf, phosphorylated MEK and phosphorylated ERK, resulting in CRC cell migration and invasion (Yang et al., 2018). Moreover, H19 regulates CRC migration and invasion through a heterogeneous nuclear ribonucleoprotein A2B1 (hnRNPA2B1)-dependent ERK/ MAPK pathway with increased expression of Raf-1 (Zhang et al., 2020).

\section{Non-Small Cell Lung Cancer}

Similarly, H19 participates in the process of NSCLC metastasis by regulating the expression of components of the MAPK signaling pathway. H19 knockdown exerts a negative effect on the migration and invasion of NSCLC A549 cells by modulating MAPK signaling pathway-related protein ERK1/2 expression and other signaling pathway protein expressions associated with cell proliferation and cell adhesion, such as metastasis-associated in colon cancer 1 (MACC1), EGFR, and $\beta$-catenin (Wang et al., 2016).

\section{Oral Cancer}

Oral cancer is a common type of cancer worldwide, and the GLOBOCAN 2018 indicated that there were 354,864 new cases and 177,384 deaths from oral cancer in 2018 (Bray et al., 2018). This has aroused attention due to its gradually increasing incidence and mortality rate. Cancer-associated fibroblasts (CAFs) play a promoting role in cancer (Chen and Song, 2019). According to the TCGA database, bioinformatic analysis showed that $\mathrm{H} 19$ is a key long noncoding RNA in oral CAFs. H19 knockdown affects oral CAFs glycolysis, proliferation, and migration processes by regulating the miR$675-5 \mathrm{p} / \mathrm{PFKFB} 3$ axis. The MAPK signaling pathway is well known to be involved in glycolysis pathways. H19 knockdown dramatically inhibits the MAPK signaling pathway by reducing the levels of ERK, phosphorylated ERK, phosphorylated p38, and JNK in oral CAFs. Consistent with the above results, H19 knockdown in CAFs exhibits an inhibitory effect on tumor growth (Yang J. et al., 2021).

\subsection{JAK/STAT Signaling Pathway}

The Janus kinase (JAK)/signal transducer and activator of the transcription (STAT) signaling pathway has been found to be a crucial oncogenic signaling pathway that participates in various physiological and pathological processes (Verhoeven et al., 2020). The major components of this pathway include cytokines and growth factors, cognate receptors, JAK family members (JAK1, JAK2, JAK3, and TYK2), and STAT family members (STAT1, STAT2, STAT3, STAT4, STAT5A, STAT5B, and STAT6). Cytokines and growth factors bind to their respective receptors and subsequently induce receptor dimerization, which results in JAK phosphorylation. Phosphorylated JAKs bind and phosphorylate the cytoplasmic tyrosine residues of the receptors, where they recruit STAT proteins. Then, STAT proteins are phosphorylated by JAKs, and phosphorylated STAT proteins form homodimers or heterodimers that translocate into the nucleus to regulate target gene expression (Gutiérrez-Hoya and Soto-Cruz, 2020). Suppressors of cytokine signaling (SOCS) proteins can inhibit the JAK/STAT signaling pathway by binding to the SH2 domains of JAKs, and protein inhibitors of activated STAT (PIAS) and protein tyrosine phosphatases (PTPs) can negatively regulate this pathway by inhibiting STAT-DNA binding and are involved in the suppression of various cytokine signals (Ou et al., 2021). The relationship between H19 and the JAK/STAT signaling pathway has been elucidated in several cancers, and the detailed mechanisms are described in the following sections.

\section{Pancreatic Cancer}

H19 is significantly highly expressed in pancreatic cancer cells and regulates the processes of the migration, invasion, EMT and chemoresistance of pancreatic cancer cells. The STAT3 pathway participates in the modulation of these processes. SCOS5, a member of the SCOS family, inhibits STAT3 activation, and $\mathrm{H} 19$ regulates the above effects via SOCS5/STAT3 signaling in pancreatic cancer cells. Interestingly, miR-675-3p, as a direct target of H19, regulates SCOS5 expression and STAT3 phosphorylation. Herein, the H19/miR-675-3p/SOCS5/STAT3 axis plays an important role in pancreatic cancer cells, which revealed potential targets for the treatment of pancreatic cancer (Wang F. et al., 2020).

\section{Non-Small Cell Lung Cancer}

H19 is overexpressed in NSCLC A549 and H1299 cells, while miR-17 is downregulated. Bioinformatics analysis based on ChipBase, LncRNAdb, and StarBase showed that H19 is negatively associated with miR-17 expression. H19 as a ceRNA 


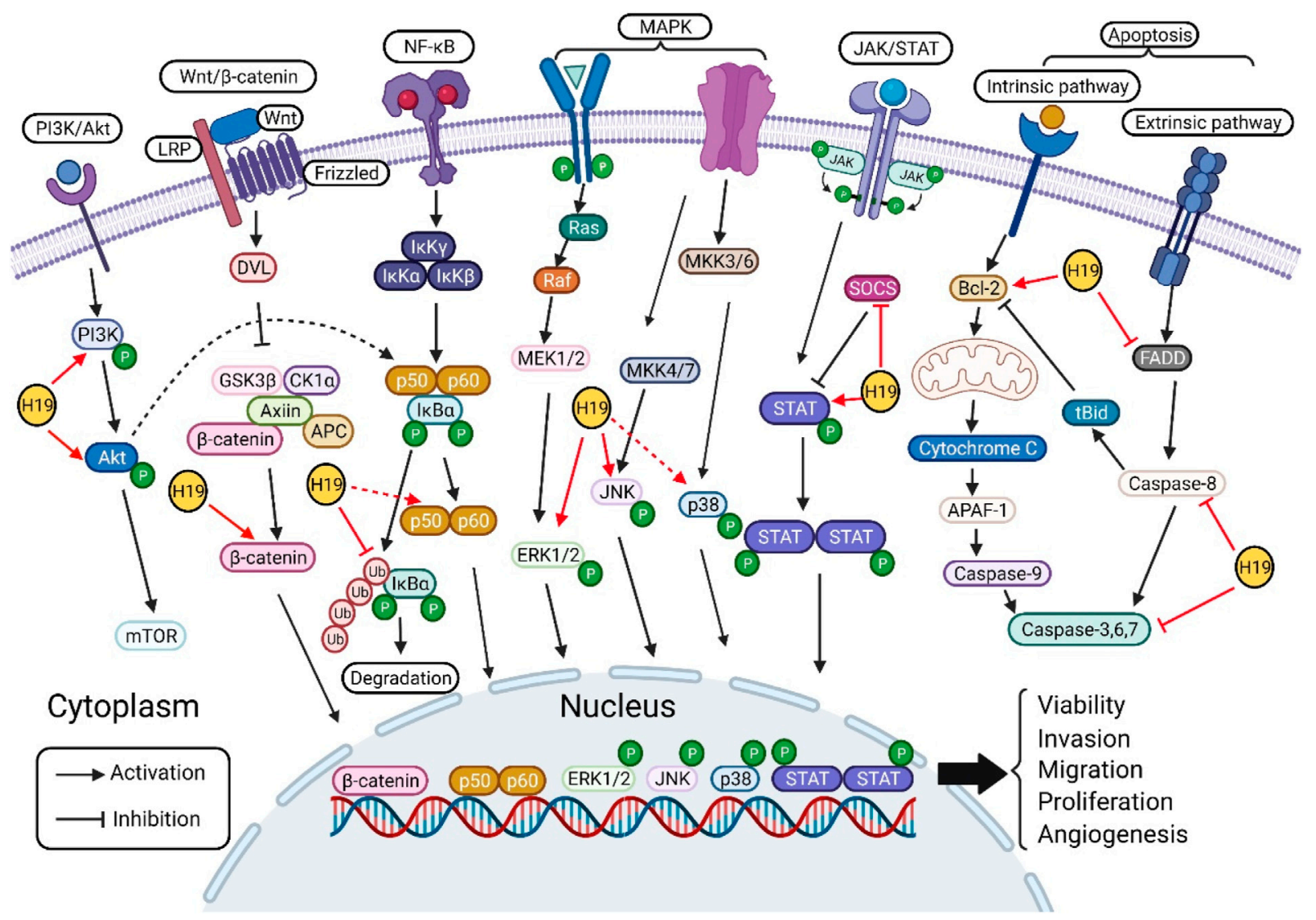

FIGURE 2 | Molecular targets of $\mathrm{H} 19$ in various oncogenic signaling pathways. $\mathrm{H} 19$ regulates the phosphorylation of PI3K and Akt in PI3K/AKt signaling pathway. $\mathrm{H} 19$ targets the key component of canonical Wnt/ $\beta$-catenin signaling pathway, increase the level of $\beta$-catenin. In NF-kB signaling pathway, $\mathrm{H} 19$ modulates the phosphorylation of $\mathrm{I}_{\kappa} \mathrm{Ba}$, p65, and p50 to regulate cell processes. $\mathrm{H} 19$ activates the phosphorylation of ERK1/2, JNK, and p38 in MAPK signaling pathway. H19 activates the phosphorylation of STAT and inhibits the expression of SOCS in STAT signaling pathway. Furthermore, H19 regulates apoptosis signaling pathway by targeting Bcl-2, FADD, caspase-8, and caspase-3. Finally, $\mathrm{H} 19$ regulates cell proliferation, proliferation, migration and invasion, angiogenesis, drug resistance and apoptosis by directly/indirectly acting on the above key molecules of signaling pathways.

directly targets miR-17. STAT3, an important member of the JAK/STAT signaling pathway, is a downstream target of miR-17 (Huang et al., 2018). In NSCLC cells, H19 regulates cell growth, migration, and invasion progression via the miR-17/STAT3 axis (Huang et al., 2018).

\subsection{Apoptosis Signaling Pathway}

Apoptosis is the classic form of programmed cell death, which plays a crucial role in the development of cancer. There are two classical apoptosis signaling pathways: the extrinsic pathway and the intrinsic pathway (Strasser et al., 1995). The interaction of Fas ligand (FasL), TNF- related apoptosis-inducing ligand (TRAIL), and TNF- $\alpha$ with their receptors induces the initiation of the extrinsic apoptotic pathway; consequently, Fas-associating protein with a novel death domain (FADD)-mediated caspase8 activation activates caspase- 8 to activate caspase- $3,-6$, and -7 , which induce cell apoptosis. Additionally, caspase- 8 processes truncated Bid and is then involved in the Bcl-2 family pathway (Ozyerli-Goknar and Bagci-Onder, 2021). The intrinsic pathway, also called the mitochondrial pathway, can activate cytokine deprivation, intracellular damage, and oncogenes; subsequently, proapoptotic members of the Bcl-2 family of proteins receive signals, leading to the release of cytochrome $\mathrm{C}$ from the mitochondria. The released cytochrome $\mathrm{C}$ triggers apoptotic protease activating factor 1 (APAF-1)-mediated activation of caspase-9, which leads to cell apoptosis by activating caspase-3, -6, and -7 (Strasser et al., 1995; Ozyerli-Goknar and Bagci-Onder, 2021). Increasing evidence has shown that $\mathrm{H} 19$, as an oncogene, induces cancer cell apoptosis.

\section{Gastric Cancer}

In gastric cancer, H19 is overexpressed and plays an important role in apoptosis. Overexpression of $\mathrm{H} 19$ promotes cell proliferation and inhibits cell apoptosis by directly targeting miR-675. FADD, as a target gene of miR-675, is involved in the effects mediated by the H19/miR-675 axis, and its expression is downregulated; subsequently, downregulation of FADD inhibits its downstream caspase- 3 and caspase- 8 expression (Yan et al., 2017). 
TABLE 1 | H19 exerts its regulatory function in several types of cancer via regulating several oncogenic signaling pathway.

\begin{tabular}{|c|c|c|c|c|c|c|}
\hline $\begin{array}{l}\text { Signaling } \\
\text { pathway }\end{array}$ & Cancer type & $\begin{array}{l}\text { Oncogene/ } \\
\text { suppressor gene }\end{array}$ & $\begin{array}{l}\mathrm{H} 19 \\
\text { expression }\end{array}$ & Molecule mechanism & Cell processes & References \\
\hline \multirow[t]{11}{*}{ PI3K/Akt } & Gastric cancer & Oncogene & Overexpression & $\uparrow p-A k t, \uparrow p-m T O R, \downarrow R U N X 1$ & $\begin{array}{l}\text { Enhance proliferation and } \\
\text { invasion }\end{array}$ & Liu et al. (2016) \\
\hline & $\begin{array}{l}\text { Hepatocellular } \\
\text { carcinoma }\end{array}$ & Suppressor gene & Downregulation & $\uparrow A k t, ~ \uparrow C d c 25 A, \downarrow G S K-3 \beta$ & $\begin{array}{l}\text { Promote migration and } \\
\text { invasion }\end{array}$ & Lv et al. (2014) \\
\hline & Pancreatic cancer & Oncogene & Overexpression & $\uparrow V G F, \uparrow p-P I 3 K, \uparrow p-A k t, \uparrow p-C R E B$ & Promote progression & Ji et al. (2019) \\
\hline & Colorectal cancer & Oncogene & Knockdown & $\downarrow M E T, \downarrow Z E B 1, \downarrow C O L 1 A 1$ & Predict prognosis & Zhong et al. (2019) \\
\hline & Breast cancer & Oncogene & Knockout & $\begin{array}{l}\uparrow \text { Bax, } \uparrow \text { cleaved caspase- } 3, \downarrow p- \\
\text { Akt, } \downarrow \text { Bcl-2 }\end{array}$ & Rescue drug resistance & Han et al. (2018) \\
\hline & Thyroid cancer & Oncogene & Knockdown & $\begin{array}{l}\uparrow B a x, \uparrow \text { caspase } 3, \downarrow B c l-2, \downarrow p- \\
\text { PI3K, } \downarrow \text { p-Akt }\end{array}$ & $\begin{array}{l}\text { Inhibit the cell viability and } \\
\text { promote apoptosis }\end{array}$ & Li et al. (2019) \\
\hline & $\begin{array}{l}\text { Non-small cell lung } \\
\text { cancer }\end{array}$ & Suppressor gene & Downregulation & $\uparrow P K M 2, \uparrow p-A k t$ & Confer drug resistance & Chen et al. (2020) \\
\hline & Melanoma & Oncogene & & $\begin{array}{l}\uparrow p \text {-Akt, } \uparrow M M P 2, \uparrow M M P 9, \uparrow \text { Slug, } \\
\downarrow E \text {-cadherin }\end{array}$ & $\begin{array}{l}\text { Promote proliferation and } \\
\text { invasion }\end{array}$ & Zhu et al. (2018) \\
\hline & Melanoma & Oncogene & Downregulation & $\downarrow p-P I 3 K, \downarrow p-A k t$ & Anti-cancer & Bi et al. (2019) \\
\hline & Hodgkin's lymphoma & Oncogene & Overexpression & $\uparrow A k t$ & Promote proliferation & Wang et al. (2019b) \\
\hline & Choriocyrarcinoma & Oncogene & Knockout & $\uparrow \mathrm{PI} \mathrm{KK}, \uparrow A \mathrm{Akt}, \uparrow \mathrm{mTOR}$ & Reduce drug resistance & Yu et al. (2019) \\
\hline \multirow[t]{8}{*}{$\begin{array}{l}\text { Canonical } \\
\text { Wnt/ } \beta \text {-catenin }\end{array}$} & Pancreatic cancer & Oncogenic & Knockdown & $\uparrow p$ - $\beta$-catenin, $\downarrow p$-LRP6, $\downarrow$ Snail & $\begin{array}{l}\text { Modulate cell proliferation } \\
\text { and migration }\end{array}$ & Sun et al. (2019) \\
\hline & Colorectal cancer & Oncogenic & Overexpression & $\begin{array}{l}\text { †progranulin, } \uparrow \beta \text {-catenin, } \uparrow c-M y c \text {, } \\
\uparrow c y c l i n \text { D1 }\end{array}$ & Promote EMT & Ding et al. (2018a) \\
\hline & Colorectal cancer & Oncogenic & Knockdown & $\downarrow \beta$-catenin & $\begin{array}{l}\text { Restore the sensitivity of } \\
\text { drug resistance }\end{array}$ & Wu et al. (2017a) \\
\hline & Breast cancer & Oncogenic & Overexpression & $\begin{array}{l}\uparrow Y W H A Z, \uparrow \text { Slug, } \uparrow \text { Snail, } \\
\uparrow \text { Vimentin, } \uparrow \text { Cyclin D1, } \uparrow \text { c-Myc, } \\
\uparrow \beta \text {-catenin, } \downarrow \text { E-cadherin }\end{array}$ & Promote EMT & Yan et al. (2020) \\
\hline & Breast cancer & Oncogenic & Overexpression & $\begin{array}{l}\text { } \text { Oestrogen receptor activated } \\
\text { Wnt signalling }\end{array}$ & $\begin{array}{l}\text { Increase the ability of self- } \\
\text { renewing }\end{array}$ & Wang et al. (2019a) \\
\hline & Glioma & Oncogenic & Knockdown & $\begin{array}{l}\uparrow G S K-3 \beta, \downarrow D V L 2, \downarrow \text { cyclin D1, } \\
\downarrow \beta \text {-catenin }\end{array}$ & $\begin{array}{l}\text { Inhibit proliferation, invasion, } \\
\text { migration, induced apoptosis }\end{array}$ & Guan et al. (2019) \\
\hline & Glioma & Oncogenic & Knockdown & $\begin{array}{l}\downarrow \text { Vascular endothelial growth } \\
\text { factor A, } \downarrow \text { MMP9, } \downarrow \text { Wnt5a, } \\
\downarrow \beta \text {-catenin }\end{array}$ & $\begin{array}{l}\text { Inhibit proliferation, } \\
\text { migration, angiogenesis }\end{array}$ & Zhou et al. (2020) \\
\hline & Bladder cancer & Oncogenic & Overexpression & $\uparrow E Z H 2, \uparrow N k d 1, \downarrow E$-cadherin & Increase metastasis & Luo et al. (2013) \\
\hline \multirow[t]{5}{*}{$\begin{array}{l}\text { Canonical } \\
\text { NF-кB }\end{array}$} & Gastric cancer & Oncogenic & Overexpression & $\uparrow p 65, \downarrow I_{\kappa} B a$ & $\begin{array}{l}\text { Promote proliferation, } \\
\text { migration, invasion }\end{array}$ & $\begin{array}{l}\text { Zhang et al. } \\
\text { (2019b) }\end{array}$ \\
\hline & Thyroid cancer & Suppressor gene & Overexpression & $\downarrow p-P|3 K, \downarrow p-\downarrow A k t, \downarrow p 65, \downarrow p-| \kappa B a$ & $\begin{array}{l}\text { Inhibit viability, migration, } \\
\text { invasion }\end{array}$ & Wang et al. (2017) \\
\hline & Melanoma & Oncogene & Downregulation & $\begin{array}{l}\uparrow l_{\kappa} B a, \downarrow p 65, \downarrow p 50, \downarrow p-P I 3 K \\
\downarrow p-A k t\end{array}$ & $\begin{array}{l}\text { Inhibit migration and } \\
\text { invasion }\end{array}$ & Liao et al. (2018) \\
\hline & Osteosarcoma & Oncogene & Downregulation & $\uparrow|\kappa B a, \downarrow p-P| 3 K, \downarrow p-A k t$ & Inhibit migration, invasion & $\begin{array}{l}\text { Zhao and Ma, } \\
\text { (2018) }\end{array}$ \\
\hline & Multiple myeloma & Oncogene & Knockdown & $\downarrow p 65, \downarrow p-\mid \kappa B a$ & Inhibit growth & Sun et al. (2017) \\
\hline \multirow[t]{6}{*}{ MAPK } & $\begin{array}{l}\text { Hepatocellular } \\
\text { carcinoma }\end{array}$ & Oncogene & Overexpression & $\uparrow M A P K 1$ & Promote aggressiveness & Ye et al. (2020) \\
\hline & $\begin{array}{l}\text { Hepatocellular } \\
\text { carcinoma }\end{array}$ & Oncogene & Downregulation & Oxidative $\uparrow$ stress, $\downarrow$ MAPK, $\downarrow$ ERK & reverse drug resistance & Ding et al. (2018b) \\
\hline & Colorectal cancer & Oncogene & Overexpression & $\uparrow$ Ras, $\uparrow p-$ Raf, $\uparrow p-E R K, ~ \uparrow p-M E K$ & $\begin{array}{l}\text { Promote migration, } \\
\text { invasion }\end{array}$ & Yang et al. (2018) \\
\hline & Colorectal cancer & Oncogene & Overexpression & $\uparrow$ Raf-1 & Promote metastasis & Zhang et al. (2020) \\
\hline & $\begin{array}{l}\text { Non-small cell lung } \\
\text { cancer }\end{array}$ & Oncogene & Overexpression & $\uparrow E R K 1 / 2$ & $\begin{array}{l}\text { Increase migration, } \\
\text { invasion }\end{array}$ & Wang et al. (2016) \\
\hline & Oral cancer & Oncogene & Knockdown & \ERK, \p-ERK, \p-p38, \JNK & $\begin{array}{l}\text { Inhibit proliferation, } \\
\text { migration, glycolysis }\end{array}$ & Yang et al. (2021a) \\
\hline \multirow[t]{2}{*}{ JAK/STAT } & Pancreatic cancer & Oncogene & Overexpression & १STAT3, \SCOS5 & Promote EMT, stemness & Wang et al. (2020a) \\
\hline & $\begin{array}{l}\text { Non-small cell lung } \\
\text { cancer }\end{array}$ & Oncogene & Overexpression & \STAT3 & $\begin{array}{l}\text { Promote cancer } \\
\text { development }\end{array}$ & Huang et al. (2018) \\
\hline \multirow[t]{4}{*}{ Apoptosis } & Gastric cancer & Oncogene & Overexpression & $\downarrow$ FADD, \caspase-3, \caspase-8 & $\begin{array}{l}\text { Promote proliferation, } \\
\text { inhibit apoptosis }\end{array}$ & Yan et al. (2017) \\
\hline & $\begin{array}{l}\text { Hepatocellular } \\
\text { carcinoma }\end{array}$ & Oncogene & Overexpression & \FADD, \caspase-3, \caspase-8 & $\begin{array}{l}\text { Promote growth, inhibit } \\
\text { apoptosis }\end{array}$ & $\begin{array}{l}\text { Ge et al., 2019a; } \\
\text { Ge et al., 2019b }\end{array}$ \\
\hline & $\begin{array}{l}\text { Non-small cell lung } \\
\text { cancer }\end{array}$ & Oncogene & Overexpression & $\uparrow B c l-2, \downarrow p 53, \downarrow B a x$ & $\begin{array}{l}\text { Promote cancer progression } \\
\text { and development }\end{array}$ & Zheng et al. (2019) \\
\hline & Cholangiocarcinoma & Oncogene & Overexpression & $\uparrow B c l-2$ & $\begin{array}{l}\text { Promote proliferation, } \\
\text { migration, invasion }\end{array}$ & Yu et al.(2020) \\
\hline
\end{tabular}




\section{Hepatocellular Carcinoma}

The effect of H19 on the components of the apoptosis signaling pathway in HCC was investigated. In HBV-induced hepatoblastoma, H19 was overexpressed and directly targeted miR-675 to regulate FADD, caspase-8, and caspase-3 expression. Moreover, H19 upregulated protein tyrosine kinase 2 (PTK2) by targeting downstream miR-138. H19, as an oncogene, inhibited cell apoptosis in hepatoblastoma via both signaling axes (Ge et al., 2019b). Recently, H19 single nucleotide polymorphisms (SNPs) were proven to be associated with cell apoptosis in HCC. The T allele of the H19 rs217727 polymorphism dramatically increased the survival rate of patients with HCC. Furthermore, the T allele of the H19 rs217727 polymorphism suppressed caspase- 3 and caspase- 8 expression via miR-675/FADD to inhibit cell apoptosis (Ge et al., 2019a).

\section{Non-Small Cell Lung Cancer}

Similarly, H19 could regulate NSCLC apoptosis by altering the expression of apoptosis-related proteins. H19 and its target gene miR-675 were significantly upregulated in NSCLC tissues and cells. p53 was found to be directly downstream of miR-675, and its expression was inversely associated with $\mathrm{H} 19$ and miR- 675 but positively associated with its downstream apoptosis-related proteins Bax/Bcl-2. Taken together, the H19/miR-675/p53 axis was found to inhibit cell apoptosis by regulating the expression of Bax and Bcl-2 (Zheng et al., 2019).

\section{Cholangiocarcinoma}

Cholangiocarcinoma is an aggressive malignant tumor originating in the extrahepatic bile duct (Banales et al., 2020). Currently, chemotherapy and radiation therapy are the main treatment therapies, but they have a poor prognosis and a shorter 5-years survival rate (7-20\%) (Su et al., 2019; Banales et al., 2020). H19 has been proven to be associated with the pathogenesis of cholangiocarcinoma, which may provide a potential therapeutic target. Bioinformatic analysis based on the TCGA and GEO databases found that $\mathrm{H} 19$ is a hub gene in cholangiocarcinoma. H19 was found to be overexpressed under the effect of the transcription factor hypoxia-inducible Factor $1 \alpha$ (HIF1a). Additionally, H19 was found to promote Bcl-2 expression by downregulating miR-612 expression, which promoted cholangiocarcinoma (Yu et al., 2020).

\section{CONCLUSION AND PERSPECTIVES}

Since its discovery, an increasing number of studies have focused on the roles of $\mathrm{H} 19$ in the pathogenesis of various types of cancer through different mechanisms, such as sponge miRNAs, interactions with proteins, and epigenetic modifications. In this review, the role of H19 in the pathogenesis of cancers, such as gastric cancer, HCC, pancreatic cancer, CRC, breast cancer, thyroid cancer, NSCLC, melanoma, Hodgkin's lymphoma, choriocarcinoma, glioma, bladder cancer, osteosarcoma, MM, oral cancer and cholangiocarcinoma, via its regulatory function in several oncogenic signaling pathways, such as the PI3K/Akt, canonical Wnt/ $\beta$-catenin, canonical NF- $\kappa B, M A P K$, JAK/STAT and apoptosis pathways, was analyzed. Furthermore, this review summarized the main regulatory effects of H19 on cell proliferation, proliferation, migration and invasion, angiogenesis, drug resistance and apoptosis of cancer by directly acting on key molecules or indirectly altering the levels of proteins associated with these signaling pathways (Figure 2) (Table 1). Based on the above results, $\mathrm{H} 19$ may be a promising therapeutic target/biomarker for the diagnosis, prevention, treatment and prognosis of different types of cancer.

Although the association of H19 with various oncogenic signaling pathways in the processes of tumorigenesis and carcinogenesis was discussed in this review, certain deficiencies and problems remain, and further studies are needed to strengthen the link. Firstly, as mentioned above, one of the functions of H19 is to regulate epigenetic modifications (Alipoor et al., 2020). In contrast to the functions of sponging miRNA and interacting proteins, only a few studies have focused on the association of H19 with epigenetic regulation. Further studies are needed to determine the role of $\mathrm{H} 19$ in epigenetic modifications in regulating the above oncogenic signaling pathways. Secondly, in addition to the above pathways, further studies should focus on $\mathrm{H} 19$ participating in cancer initiation and progression by acting on other pathways, such as the p53, Hippo, Sonic Hedgehog (Shh), and PTEN signaling pathways. Thirdly, increasing evidence has shown that H19 plays an important role in various cancers in vivo and in vitro; nevertheless, clinical trials on $\mathrm{H} 19$ in cancer are lacking, and it is necessary to conduct more clinical trials. Additionally, the combination of basic research on $\mathrm{H} 19$ and clinical trials may be more proficient for the diagnosis, prevention, treatment and prognosis of various cancers. Fourth, H19 plays dual roles in cancer. In thyroid cancer, H19 exerts an oncogenic function to modulate cell viability and apoptosis by regulating the PI3K/Akt pathway, while another study demonstrated that H19, as a suppressor gene, inhibited cell viability, migration, and invasion via insulin receptor substrate I-mediated PI3K/Akt and NF- $\mathrm{BB}$ pathways in thyroid cancer cells (Wang et al., 2017; Li et al., 2019). The reason why H19 shows discrepancy results needs to be further investigated. Lastly, increasing evidence had shown that circulating H19 could as a biomarker for monitoring cancer progression (Wang et al., 2018; Zhong et al., 2020), however, the detail mechanisms are not clear in various types of cancer. Whether the regulatory mechanism of circulating H19 in cancer is the same as $\mathrm{H} 19$, which needs to be further investigated in the future.

\section{AUTHOR CONTRIBUTIONS}

BW, YZ, and YY drafted the manuscript; CZ, QL, ZL, and CL completed the figures and table; YT and FX managed the article design, reviewed the manuscript; YT provided funding support. All authors have read and approved the final manuscript.

\section{FUNDING}

This work supported in part by the Natural Science Foundation of China (No. 81974377) and the Scientific Research Project of Education Department of Liaoning Province (No. JC2019017) 345 Talent Project. 


\section{REFERENCES}

Alipoor, B., Parvar, S. N., Sabati, Z., Ghaedi, H., and Ghasemi, H. (2020). An Updated Review of the H19 lncRNA in Human Cancer: Molecular Mechanism and Diagnostic and Therapeutic Importance. Mol. Biol. Rep. 47, 6357-6374. doi:10.1007/s11033-020-05695-x

Anton, D. B., Ducati, R. G., Timmers, L., Laufer, S., and Goettert, M. I. (2021). A Special View of what Was Almost Forgotten: P38 8 MAPK. Cancers (Basel) 13, 77. doi:10.3390/cancers13092077

Banales, J. M., Marin, J. J. G., Lamarca, A., Rodrigues, P. M., Khan, S. A., Roberts, L. R., et al. (2020). Cholangiocarcinoma 2020: the Next Horizon in Mechanisms and Management. Nat. Rev. Gastroenterol. Hepatol. 17, 557-588. doi:10.1038/ s41575-020-0310-z

Bazot, M., Cortez, A., Sananes, S., and Buy, J.-N. (2004). Imaging of Pure Primary Ovarian Choriocarcinoma. Am. J. Roentgenology 182, 1603-1604. doi:10.2214/ ajr.182.6.1821603

Berteaux, N., Lottin, S., Monté, D., Pinte, S., Quatannens, B., Coll, J., et al. (2005). H19 mRNA-like Noncoding RNA Promotes Breast Cancer Cell Proliferation through Positive Control by E2F1. J. Biol. Chem. 280, 29625-29636. doi:10.1074/jbc.m504033200

Bi, Y., Fu, Y., Wang, S., Chen, X., and Cai, X. (2019). Schizandrin A Exerts Antitumor Effects on A375 Cells by Down-Regulating H19. Braz. J. Med. Biol. Res. 52, e8385. doi:10.1590/1414-431X20198385

Bilic', J., Huang, Y.-L., Davidson, G., Zimmermann, T., Cruciat, C.-M., Bienz, M., et al. (2007). Wnt Induces LRP6 Signalosomes and Promotes Dishevelled-dependent LRP6 Phosphorylation. Science 316, 1619-1622. doi:10.1126/science.1137065

Botter, S. M., Neri, D., and Fuchs, B. (2014). Recent Advances in Osteosarcoma. Curr. Opin. Pharmacol. 16, 15-23. doi:10.1016/j.coph.2014.02.002

Braicu, C., Buse, M., Busuioc, C., Drula, R., Gulei, D., Raduly, L., et al. (2019). A Comprehensive Review on MAPK: A Promising Therapeutic Target in Cancer. Cancers (Basel) 11, 1618. doi:10.3390/cancers11101618

Brannan, C. I., Dees, E. C., Ingram, R. S., and Tilghman, S. M. (1990). The Product of the H19 Gene May Function as an RNA. Mol. Cel. Biol. 10, 28-36. doi:10.1128/mcb.10.1.28

Bray, F., Ferlay, J., Soerjomataram, I., Siegel, R. L., Torre, L. A., and Jemal, A. (2018). Global Cancer Statistics 2018: GLOBOCAN Estimates of Incidence and Mortality Worldwide for 36 Cancers in 185 Countries. CA: A Cancer J. Clinicians 68, 394-424. doi:10.3322/caac.21492

Charles Richard, J. L., and Eichhorn, P. J. A. (2018). Platforms for Investigating LncRNA Functions. SLAS TECHNOLOGY: Translating Life Sci. Innovation 23, 493-506. doi:10.1177/2472630318780639

Chen, C., Liu, W.-R., Zhang, B., Zhang, L.-M., Li, C.-G., Liu, C., et al. (2020). LncRNA H19 Downregulation Confers Erlotinib Resistance through Upregulation of PKM2 and Phosphorylation of AKT in EGFR-Mutant Lung Cancers. Cancer Lett. 486, 58-70. doi:10.1016/j.canlet.2020.05.009

Chen, X., and Song, E. (2019). Turning Foes to Friends: Targeting CancerAssociated Fibroblasts. Nat. Rev. Drug Discov. 18, 99-115. doi:10.1038/ s41573-018-0004-1

Cheng, T., Xu, M., Qin, B., Wu, J., Tu, Y., Kang, L., et al. (2019). IncRNA H19 Contributes to Oxidative Damage Repair in the Early Age-related Cataract by Regulating miR-29a/TDG axis. J. Cel Mol Med 23, 6131-6139. doi:10.1111/ jcmm.14489

Choong, O. K., Chen, C.-Y., Zhang, J., Lin, J.-H., Lin, P.-J., Ruan, S.-C., et al. (2019). Hypoxia-induced H19/YB-1 cascade Modulates Cardiac Remodeling after Infarction. Theranostics 9, 6550-6567. doi:10.7150/thno.35218

Cowan, A. J., Allen, C., Barac, A., Basaleem, H., Bensenor, I., Curado, M. P., et al. (2018). Global Burden of Multiple Myeloma. JAMA Oncol. 4, 1221-1227. doi:10.1001/jamaoncol.2018.2128

Davidson, G., Shen, J., Huang, Y.-L., Su, Y., Karaulanov, E., Bartscherer, K., et al. (2009). Cell Cycle Control of Wnt Receptor Activation. Develop. Cel 17, 788-799. doi:10.1016/j.devcel.2009.11.006

Deangelis, L. M. (2001). Brain Tumors. N. Engl. J. Med. 344, 114-123. doi:10.1056/ nejm200101113440207

Ding, D., Li, C., Zhao, T., Li, D., Yang, L., and Zhang, B. (2018a). LncRNA H19/ miR-29b-3p/PGRN Axis Promoted Epithelial-Mesenchymal Transition of Colorectal Cancer Cells by Acting on Wnt Signaling. Mol. Cell 41, 423-435. doi:10.14348/molcells.2018.2258
Ding, K., Liao, Y., Gong, D., Zhao, X., and Ji, W. (2018b). Effect of Long Noncoding RNA H19 on Oxidative Stress and Chemotherapy Resistance of CD133+ Cancer Stem Cells via the MAPK/ERK Signaling Pathway in Hepatocellular Carcinoma. Biochem. Biophysical Res. Commun. 502, 194-201. doi:10.1016/ j.bbrc.2018.05.143

Du, J., Shao, Y., Hu, Y., Chen, Y., Cang, J., Chen, X., et al. (2021). Multifunctional Liposomes Enable Active Targeting and Twinfilin 1 Silencing to Reverse Paclitaxel Resistance in Brain Metastatic Breast Cancer. ACS Appl. Mater. Inter. 13, 23396-23409. doi:10.1021/acsami.1c02822

Gan, L., Lv, L., and Liao, S. (2019). Long Non-coding RNA H19 R-egulates C-ell G-rowth and M-etastasis via the miR-22-3p/Snaill axis in G-astric C-ancer. Int. J. Oncol. 54, 2157-2168. doi:10.3892/ijo.2019.4773

Ge, L., Wang, Q., Hu, S., and Yang, X. (2019a). Rs217727 Polymorphism in H19 Promotes Cell Apoptosis by Regulating the Expressions of H19 and the Activation of its Downstream Signaling Pathway. J. Cel Physiol 234, 7279-7291. doi:10.1002/jcp.27485

Ge, L., Zhang, X., Hu, S., Song, Y., Kong, J., Zhang, B., et al. (2019b). H19 Suppresses the Growth of Hepatoblastoma Cells by Promoting Their Apoptosis via the Signaling Pathways of miR-675/FADD and miR-138/PTK2. J. Cel Biochem 120, 5218-5231. doi:10.1002/jcb.27797

Ghafouri-Fard, S., Esmaeili, M., and Taheri, M. (2020). H19 lncRNA: Roles in Tumorigenesis. Biomed. Pharmacother. 123, 109774. doi:10.1016/j.biopha.2019.109774

Gibb, E. A., Brown, C. J., and Lam, W. L. (2011). The Functional Role of Long Noncoding RNA in Human Carcinomas. Mol. Cancer 10, 38. doi:10.1186/14764598-10-38

Giovarelli, M., Bucci, G., Ramos, A., Bordo, D., Wilusz, C. J., Chen, C.-Y., et al. (2014). H19 Long Noncoding RNA Controls the mRNA Decay Promoting Function of KSRP. Proc. Natl. Acad. Sci. USA 111, E5023-E5028. doi:10.1073/ pnas.1415098111

Guan, N., Wang, R., Guo, W. S., Lai, Y. J., Zhang, Y. D., and Cheng, Y. Y. (2019). Long Non-coding RNA H19 Regulates the Development of Gliomas through the Wnt/ $\beta$-Catenin Signaling Pathway. Eur. Rev. Med. Pharmacol. Sci. 23, 4243-4253. doi:10.26355/eurrev_201905_17929

Guney Eskiler, G., Cecener, G., Egeli, U., and Tunca, B. (2018). Triple Negative Breast Cancer: New Therapeutic Approaches and BRCAstatus. Apmis 126, 371-379. doi:10.1111/apm.12836

Gutiérrez-Hoya, A., and Soto-Cruz, I. (2020). Role of the JAK/STAT Pathway in Cervical Cancer: Its Relationship with HPV E6/E7 Oncoproteins. Cells 9, 2297. doi:10.3390/cells9102297

Han, J., Han, B., Wu, X., Hao, J., Dong, X., Shen, Q., et al. (2018). Knockdown of IncRNA H19 Restores Chemo-Sensitivity in Paclitaxel-Resistant TripleNegative Breast Cancer through Triggering Apoptosis and Regulating Akt Signaling Pathway. Toxicol. Appl. Pharmacol. 359, 55-61. doi:10.1016/ j.taap.2018.09.018

He, Y., Meng, X.-M., Huang, C., Wu, B.-M., Zhang, L., Lv, X.-W., et al. (2014). Long Noncoding RNAs: Novel Insights into Hepatocelluar Carcinoma. Cancer Lett. 344, 20-27. doi:10.1016/j.canlet.2013.10.021

Hodis, E., Watson, I. R., Kryukov, G. V., Arold, S. T., Imielinski, M., Theurillat, J.P., et al. (2012). A Landscape of Driver Mutations in Melanoma. Cell 150, 251-263. doi:10.1016/j.cell.2012.06.024

Hoesel, B., and Schmid, J. A. (2013). The Complexity of NF-Kb Signaling in Inflammation and Cancer. Mol. Cancer 12, 86. doi:10.1186/1476-4598-12-86

Hu, H.-H., Cao, G., Wu, X.-Q., Vaziri, N. D., and Zhao, Y.-Y. (2020). Wnt Signaling Pathway in Aging-Related Tissue Fibrosis and Therapies. Ageing Res. Rev. 60, 101063. doi:10.1016/j.arr.2020.101063

Huang, Z., Lei, W., Hu, H. B., Zhang, H., and Zhu, Y. (2018). H19 Promotes Non-small-cell Lung Cancer (NSCLC) Development through STAT3 Signaling via Sponging miR-17. J. Cel Physiol 233, 6768-6776. doi:10.1002/jcp.26530

Ji, M., Yao, Y., Liu, A., Shi, L., Chen, D., Tang, L., et al. (2019). IncRNA H19 Binds VGF and Promotes pNEN Progression via PI3K/AKT/CREB Signaling. Endocr. Relat. Cancer 26, 643-658. doi:10.1530/erc-18-0552

Kim, W.-J., Kim, E.-J., Kim, S.-K., Kim, Y.-J., Ha, Y.-S., Jeong, P., et al. (2010). Predictive Value of Progression-Related Gene Classifier in Primary Nonmuscle Invasive Bladder Cancer. Mol. Cancer 9, 3. doi:10.1186/1476-45989-3

Li, X., Li, Q., Jin, X., Guo, H., and Li, Y. (2019). Long Non-coding RNA H19 Knockdown Inhibits the Cell Viability and Promotes Apoptosis of Thyroid 
Cancer Cells through Regulating the PI3K/AKT Pathway. Exp. Ther. Med. 18, 1863-1869. doi:10.3892/etm.2019.7720

Liao, Z., Zhao, J., and Yang, Y. (2018). Downregulation of lncRNA H19 Inhibits the Migration and Invasion of Melanoma Cells by Inactivating the NF- $\mathrm{kB}$ and PI3K/Akt S-ignaling P-athways. Mol. Med. Rep. 17, 7313-7318. doi:10.3892/ mmr.2018.8782

Liu, C., Yang, Z., Wu, J., Zhang, L., Lee, S., Shin, D.-J., et al. (2018). Long Noncoding RNA H19 Interacts with Polypyrimidine Tract-Binding Protein 1 to Reprogram Hepatic Lipid Homeostasis. Hepatology 67, 1768-1783. doi:10.1002/hep.29654

Liu, G., Xiang, T., Wu, Q.-F., and Wang, W.-X. (2016). Long Noncoding RNA H19-Derived miR-675 Enhances Proliferation and Invasion via RUNX1 in Gastric Cancer Cells. Oncol. Res. 23, 99-107. doi:10.3727/ $096504015 \times 14496932933575$

Liu, S., Qiu, J., Tang, X., Cui, H., Zhang, Q., and Yang, Q. (2019). LncRNA-H19 Regulates Cell Proliferation and Invasion of Ectopic Endometrium by Targeting ITGB3 via Modulating miR-124-3p. Exp. Cel Res. 381, 215-222. doi:10.1016/ j.yexcr.2019.05.010

Luo, M., Li, Z., Wang, W., Zeng, Y., Liu, Z., and Qiu, J. (2013). Long Non-coding RNA H19 Increases Bladder Cancer Metastasis by Associating with EZH2 and Inhibiting E-Cadherin Expression. Cancer Lett. 333, 213-221. doi:10.1016/ j.canlet.2013.01.033

Lv, J., Ma, L., Chen, X.-l., Huang, X.-h., and Wang, Q. (2014). Downregulation of LncRNAH19 and MiR-675 Promotes Migration and Invasion of Human Hepatocellular Carcinoma Cells through AKT/GSK-3 $\beta / C d c 25$ A Signaling Pathway. J. Huazhong Univ. Sci. Technol. [Med. Sci. 34, 363-369. doi:10.1007/s11596-014-1284-2

Ma, H., Yuan, L., Li, W., Xu, K., and Yang, L. (2018). The LncRNA H19/miR-193a$3 \mathrm{p}$ axis Modifies the Radio-resistance and Chemotherapeutic Tolerance of Hepatocellular Carcinoma Cells by Targeting PSEN1. J. Cel. Biochem. 119, 8325-8335. doi:10.1002/jcb.26883

Ma, L., Tian, X., Wang, F., Zhang, Z., Du, C., Xie, X., et al. (2016). The Long Noncoding RNA H19 Promotes Cell Proliferation via E2F-1 in Pancreatic Ductal Adenocarcinoma. Cancer Biol. Ther. 17, 1051-1061. doi:10.1080/ 15384047.2016.1219814

Marášek, P., Dzijak, R., Studenyak, I., Fišerová, J., Uličná, L., Novák, P., et al. (2015). Paxillin-dependent Regulation of IGF2 and H19 Gene Cluster Expression. J. Cel Sci 128, 3106-3116.

Minnie, S. A., and Hill, G. R. (2020). Immunotherapy of Multiple Myeloma. J. Clin. Invest. 130, 1565-1575. doi:10.1172/jci129205

Monnier, P., Martinet, C., Pontis, J., Stancheva, I., Ait-Si-Ali, S., and Dandolo, L. (2013). H19 IncRNA Controls Gene Expression of the Imprinted Gene Network by Recruiting MBD1. Proc. Natl. Acad. Sci. 110, 20693-20698. doi:10.1073/ pnas. 1310201110

Ou, A., Ott, M., Fang, D., and Heimberger, A. B. (2021). The Role and Therapeutic Targeting of JAK/STAT Signaling in Glioblastoma. Cancers (Basel) 13, 437. doi:10.3390/cancers13030437

Ozyerli-Goknar, E., and Bagci-Onder, T. (2021). Epigenetic Deregulation of Apoptosis in Cancers. Cancers (Basel) 13, 3210. doi:10.3390/ cancers 13133210

Paez, J. G., Jänne, P. A., Lee, J. C., Tracy, S., Greulich, H., Gabriel, S., et al. (2004). EGFR Mutations in Lung Cancer: Correlation with Clinical Response to Gefitinib Therapy. Science 304, 1497-1500. doi:10.1126/ science.1099314

Peluso, I., Yarla, N. S., Ambra, R., Pastore, G., and Perry, G. (2019). MAPK Signalling Pathway in Cancers: Olive Products as Cancer Preventive and Therapeutic Agents. Semin. Cancer Biol. 56, 185-195. doi:10.1016/ j.semcancer.2017.09.002

Pope, C., Mishra, S., Russell, J., Zhou, Q., and Zhong, X. B. (2017). Targeting H19, an Imprinted Long Non-coding RNA, in Hepatic Functions and Liver Diseases. Diseases 5, 11. doi:10.3390/diseases5010011

Runge, S., Nielsen, F. C., Nielsen, J., Lykke-Andersen, J., Wewer, U. M., and Christiansen, J. (2000). H19 RNA Binds Four Molecules of Insulin-like Growth Factor II mRNA-Binding Protein. J. Biol. Chem. 275, 29562-29569. doi:10.1074/jbc.m001156200

Schoenfelder, S., Smits, G., Fraser, P., Reik, W., and Paro, R. (2007). Non-coding Transcripts in theH19imprinting Control Region Mediate Gene Silencing in
transgenicDrosophila. $\quad E M B O \quad$ Rep. $\quad 8, \quad 1068-1073 . \quad$ doi:10.1038/ sj.embor.7401094

Song, Y., Liu, C., Liu, X., Trottier, J., Beaudoin, M., Zhang, L., et al. (2017). H19 Promotes Cholestatic Liver Fibrosis by Preventing ZEB1-Mediated Inhibition of Epithelial Cell Adhesion Molecule. Hepatology 66, 1183-1196. doi:10.1002/ hep. 29209

Strasser, A., Harris, A. W., Huang, D. C., Krammer, P. H., and Cory, S. (1995). Bcl2 and Fas/APO-1 Regulate Distinct Pathways to Lymphocyte Apoptosis. EMBO J. 14, 6136-6147. doi:10.1002/j.1460-2075.1995.tb00304.x

Su, K., Wang, N., Shao, Q., Liu, H., Zhao, B., and Ma, S. (2021). The Role of a ceRNA Regulatory Network Based on IncRNA MALAT1 Site in Cancer Progression. Biomed. Pharmacother. 137, 111389. doi:10.1016/ j.biopha.2021.111389

Su, Z.-j., Liu, X.-y., Zhang, J.-h., Ke, S.-y., and Fei, H.-j. (2019). Neurotensin Promotes Cholangiocarcinoma Metastasis via the EGFR/AKT Pathway. Gene 687, 143-150. doi:10.1016/j.gene.2018.10.062

Sun, L., Li, J., Yan, W., Yao, Z., Wang, R., Zhou, X., et al. (2021). H19 Promotes Aerobic Glycolysis, Proliferation, and Immune Escape of Gastric Cancer Cells through the microRNA-519d-3p/lactate Dehydrogenase A axis. Cancer Sci. 112, 2245-2259. doi:10.1111/cas.14896

Sun, Y., Pan, J., Zhang, N., Wei, W., Yu, S., and Ai, L. (2017). Knockdown of Long Non-coding RNA H19 Inhibits Multiple Myeloma Cell Growth via NF-Kb Pathway. Sci. Rep. 7, 18079. doi:10.1038/s41598-017-18056-9

Sun, Y., Zhu, Q., Yang, W., Shan, Y., Yu, Z., Zhang, Q., et al. (2019). LncRNA H19/miR-194/PFTK1 axis Modulates the Cell Proliferation and Migration of Pancreatic Cancer. J. Cel Biochem 120, 3874-3886. doi:10.1002/ jcb. 27669

Taniguchi, K., and Karin, M. (2018). NF- $\mathrm{kB}$, Inflammation, Immunity and Cancer: Coming of Age. Nat. Rev. Immunol. 18, 309-324. doi:10.1038/ nri.2017.142

Teng, Y., Fan, Y., Ma, J., Lu, W., Liu, N., Chen, Y., et al. (2021). The PI3K/Akt Pathway: Emerging Roles in Skin Homeostasis and a Group of Non-malignant Skin Disorders. Cells 10, 1219. doi:10.3390/cells10051219

Thorvaldsen, J. L., Duran, K. L., and Bartolomei, M. S. (1998). Deletion of the H19 Differentially Methylated Domain Results in Loss of Imprinted Expression of H19 and Igf2. Genes Dev. 12, 3693-3702. doi:10.1101/ gad.12.23.3693

Verhoeven, Y., Tilborghs, S., Jacobs, J., De Waele, J., Quatannens, D., Deben, C., et al. (2020). The Potential and Controversy of Targeting STAT Family Members in Cancer. Semin. Cancer Biol. 60, 41-56. doi:10.1016/ j.semcancer.2019.10.002

Wang, C., Liu, X., Chen, Z., Huang, H., Jin, Y., Kolokythas, A., et al. (2013). Polycomb Group Protein EZH2-Mediated E-Cadherin Repression Promotes Metastasis of Oral Tongue Squamous Cell Carcinoma. Mol. Carcinog. 52, 229-236. doi:10.1002/mc.21848

Wang, F., Rong, L., Zhang, Z., Li, M., Ma, L., Ma, Y., et al. (2020a). LncRNA H19Derived miR-675-3p Promotes Epithelial-Mesenchymal Transition and Stemness in Human Pancreatic Cancer Cells by Targeting the STAT3 Pathway. J. Cancer 11, 4771-4782. doi:10.7150/jca.44833

Wang, J., Yang, K., Yuan, W., and Gao, Z. (2018). Determination of Serum Exosomal H19 as a Noninvasive Biomarker for Bladder Cancer Diagnosis and Prognosis. Med. Sci. Monit. 24, 9307-9316. doi:10.12659/ msm.912018

Wang, J., Zhao, L., Shang, K., Liu, F., Che, J., Li, H., et al. (2020b). Long Non-coding RNA H19, a Novel Therapeutic Target for Pancreatic Cancer. Mol. Med. 26, 30. doi:10.1186/s10020-020-00156-4

Wang, L., Sun, Y., Yi, J., Wang, X., Liang, J., Pan, Z., et al. (2016). Targeting H19 by Lentivirus-Mediated RNA Interference Increases A549 Cell Migration and Invasion. Exp. Lung Res. 42, 346-353. doi:10.1080/01902148.2016.1223229

Wang, M., Li, Y., Xiao, G.-D., Zheng, X.-Q., Wang, J.-C., Xu, C.-W., et al. (2019a). H19 Regulation of Oestrogen Induction of Symmetric Division Is Achieved by Antagonizing Let-7c in Breast Cancer Stem-like Cells. Cell Prolif 52, e12534. doi: $10.1111 /$ cpr. 12534

Wang, P., Liu, G., Xu, W., Liu, H., Bu, Q., and Sun, D. (2017). Long Noncoding RNA H19 Inhibits Cell Viability, Migration, and Invasion via Downregulation of IRS-1 in Thyroid Cancer Cells. Technol. Cancer Res. Treat. 16, 1102-1112. doi:10.1177/1533034617733904 
Wang, Y., Wang, L., and Sui, M. (2019b). Long Non-coding RNA H19 Promotes Proliferation of Hodgkin's Lymphoma via AKT Pathway. J. Buon 24, 763-769.

Wei, L. Q., Li, L., Lu, C., Liu, J., Chen, Y., and Wu, H. (2019). Involvement of H19/ miR-326 axis in Hepatocellular Carcinoma Development through Modulating TWIST1. J. Cel Physiol 234, 5153-5162. doi:10.1002/jcp.27319

Wu, K.-f., Liang, W.-C., Feng, L., Pang, J.-x., Waye, M. M.-Y., Zhang, J.-F., et al. (2017a). H19 Mediates Methotrexate Resistance in Colorectal Cancer through Activating Wnt/ $\beta$-Catenin Pathway. Exp. Cel Res. 350, 312-317. doi:10.1016/ j.yexcr.2016.12.003

Wu, W., Hu, Q., Nie, E., Yu, T., Wu, Y., Zhi, T., et al. (2017b). Hypoxia Induces H19 Expression through Direct and Indirect Hif-1 1 Activity, Promoting Oncogenic Effects in Glioblastoma. Sci. Rep. 7, 45029. doi:10.1038/srep45029

Xu, J. L., Hua, T., Ding, J., Fan, Y., Liu, Z. J., and Lian, J. W. (2019). FOXF2 Aggravates the Progression of Non-small Cell Lung Cancer through Targeting lncRNA H19 to Downregulate PTEN. Eur. Rev. Med. Pharmacol. Sci. 23, 10796-10802. doi:10.26355/eurrev_201912_19782

Xu, X., Zhang, M., Xu, F., and Jiang, S. (2020). Wnt Signaling in Breast Cancer: Biological Mechanisms, Challenges and Opportunities. Mol. Cancer 19, 165. doi:10.1186/s12943-020-01276-5

Yan, J., Zhang, Y., She, Q., Li, X., Peng, L., Wang, X., et al. (2017). Long Noncoding RNA H19/miR-675 Axis Promotes Gastric Cancer via FADD/Caspase 8/ Caspase 3 Signaling Pathway. Cell Physiol Biochem 42, 2364-2376. doi:10.1159/000480028

Yan, L., Yang, S., Yue, C. X., Wei, X. Y., Peng, W., Dong, Z. Y., et al. (2020). Long Noncoding RNA H19 Acts as a miR -340-3p Sponge to Promote Epithelialmesenchymal Transition by Regulating YWHAZ Expression in Paclitaxelresistant Breast Cancer Cells. Environ. Toxicol. 35, 1015-1028. doi:10.1002/ tox.22938

Yang, F., Bi, J., Xue, X., Zheng, L., Zhi, K., Hua, J., et al. (2012). Up-regulated Long Non-coding RNA H19 Contributes to Proliferation of Gastric Cancer Cells. Febs $j$ 279, 3159-3165. doi:10.1111/j.1742-4658.2012.08694.x

Yang, J., Shi, X., Yang, M., Luo, J., Gao, Q., Wang, X., et al. (2021a). Glycolysis Reprogramming in Cancer-Associated Fibroblasts Promotes the Growth of Oral Cancer through the lncRNA H19/miR-675-5p/PFKFB3 Signaling Pathway. Int. J. Oral Sci. 13, 12. doi:10.1038/s41368-021-00115-7

Yang, W., Redpath, R. E., Zhang, C., and Ning, N. (2018). Long Non-coding RNA H19 Promotes the Migration and Invasion of colon Cancer Cells via MAPK Signaling Pathway. Oncol. Lett. 16, 3365-3372. doi:10.3892/ol.2018.9052

Yang, Z., Zhang, T., Han, S., Kusumanchi, P., Huda, N., Jiang, Y., et al. (2021b). Long Noncoding RNA H19 - a New Player in the Pathogenesis of Liver Diseases. Translational Res. 230, 139-150. doi:10.1016/j.trsl.2020.11.010

Ye, A., He, H., and Kim, J. (2016). PEG3 Binds to H19-ICR as a Transcriptional Repressor. Epigenetics 11, 889-900. doi:10.1080/15592294.2016.1255385

Ye, Y., Guo, J., Xiao, P., Ning, J., Zhang, R., Liu, P., et al. (2020). Macrophagesinduced Long Noncoding RNA H19 Up-Regulation Triggers and Activates the miR-193b/MAPK1 axis and Promotes Cell Aggressiveness in Hepatocellular Carcinoma. Cancer Lett. 469, 310-322. doi:10.1016/j.canlet.2019.11.001

Yu, A., Zhao, L., Kang, Q., Li, J., Chen, K., and Fu, H. (2020). Transcription Factor HIFla Promotes Proliferation, Migration, and Invasion of Cholangiocarcinoma via Long Noncoding RNA H19/microRNA-612/Bcl-2 axis. Translational Res. 224, 26-39. doi:10.1016/j.trsl.2020.05.010

Yu, S., Wu, C., Tan, Q., and Liu, H. (2019). Long Noncoding RNA H19 Promotes Chemotherapy Resistance in Choriocarcinoma Cells. J. Cel Biochem 120, 15131-15144. doi:10.1002/jcb.28775

Zeke, A., Misheva, M., Reményi, A., and Bogoyevitch, M. A. (2016). JNK Signaling: Regulation and Functions Based on Complex Protein-Protein Partnerships. Microbiol. Mol. Biol. Rev. 80, 793-835. doi:10.1128/mmbr.00043-14

Zhang, J., Han, C., Ungerleider, N., Chen, W., Song, K., Wang, Y., et al. (2019a). A Transforming Growth Factor- $\beta$ and H19 Signaling Axis in Tumor-Initiating Hepatocytes that Regulates Hepatic Carcinogenesis. Hepatology 69, 1549-1563. doi:10.1002/hep.30153
Zhang, L., Zhou, Y., Huang, T., Cheng, A. S., Yu, J., Kang, W., et al. (2017). The Interplay of LncRNA-H19 and its Binding Partners in Physiological Process and Gastric Carcinogenesis. Int. J. Mol. Sci. 18, 450. doi:10.3390/ijms18020450

Zhang, Y., Huang, W., Yuan, Y., Li, J., Wu, J., Yu, J., et al. (2020). Long Non-coding RNA H19 Promotes Colorectal Cancer Metastasis via Binding to hnRNPA2B1. J. Exp. Clin. Cancer Res. 39, 141. doi:10.1186/s13046-020-01619-6

Zhang, Y., and Wang, X. (2020). Targeting the Wnt/ $\beta$-Catenin Signaling Pathway in Cancer. J. Hematol. Oncol. 13, 165. doi:10.1186/s13045-020-00990-3

Zhang, Y., Yan, J., Li, C., Wang, X., Dong, Y., Shen, X., et al. (2019b). LncRNA H19 Induced by helicobacter Pylori Infection Promotes Gastric Cancer Cell Growth via Enhancing NF-Kb-Induced Inflammation. J. Inflamm. 16, 23. doi:10.1186/ s12950-019-0226-y

Zhao, J., and Ma, S. T. (2018). Downregulation of IncRNA H19 Inhibits Migration and Invasion of Human Osteosarcoma through the NF-Kb Pathway. Mol. Med. Rep. 17, 7388-7394. doi:10.3892/mmr.2018.8746

Zheng, J. F., Guo, N. H., Zi, F. M., and Cheng, J. (2020). Long Noncoding RNA H19 Promotes Tumorigenesis of Multiple Myeloma by Activating BRD4 Signaling by Targeting MicroRNA 152-3p. Mol. Cel Biol 40, e00382. doi:10.1128/ MCB.00382-19

Zheng, Z. H., Wu, D. M., Fan, S. H., Zhang, Z. F., Chen, G. Q., and Lu, J. (2019). Upregulation of miR-675-5p Induced by IncRNA H19 Was Associated with Tumor Progression and Development by Targeting Tumor Suppressor P53 in Non-small Cell Lung Cancer. J. Cel Biochem 120, 18724-18735. doi:10.1002/ jcb. 29182

Zhong, G., Wang, K., Li, J., Xiao, S., Wei, W., and Liu, J. (2020). Determination of Serum Exosomal H19 as a Noninvasive Biomarker for Breast Cancer Diagnosis. Onco Targets Ther. 13, 2563-2571. doi:10.2147/ott.s243601

Zhong, M.-E., Chen, Y., Zhang, G., Xu, L., Ge, W., and Wu, B. (2019). LncRNA H19 Regulates PI3K-Akt Signal Pathway by Functioning as a ceRNA and Predicts Poor Prognosis in Colorectal Cancer: Integrative Analysis of Dysregulated ncRNA-Associated ceRNA Network. Cancer Cel Int 19, 148. doi:10.1186/ s12935-019-0866-2

Zhong, X., Zhang, C., Diao, Y., Liao, S., Ling, Q., Zhang, Z., et al. (2021). The LncRNA H19/microRNA-29b-3p/HMGB1 Signaling axis Contributes to the Regulation of Lung Cancer Cell Growth. FEBS Open Bio. doi:10.1002/22115463.13103

Zhou, Q., Liu, Z. Z., Wu, H., and Kuang, W. L. (2020). LncRNA H19 Promotes Cell Proliferation, Migration, and Angiogenesis of Glioma by Regulating Wnt5a/ $\beta$-Catenin Pathway via Targeting miR-342. Cell Mol Neurobiol. doi:10.1007/ s10571-020-00995-Z

Zhu, X., Li, W., and Meng, Q. (2018). LncRNA H19 Promotes Proliferation and Invasion in A375 Human Melanoma Cell Line. Int. J. Clin. Exp. Pathol. 11, 1063-1073.

Conflict of Interest: The authors declare that the research was conducted in the absence of any commercial or financial relationships that could be construed as a potential conflict of interest.

Publisher's Note: All claims expressed in this article are solely those of the authors and do not necessarily represent those of their affiliated organizations, or those of the publisher, the editors and the reviewers. Any product that may be evaluated in this article, or claim that may be made by its manufacturer, is not guaranteed or endorsed by the publisher.

Copyright $\odot 2021 \mathrm{Wu}$, Zhang, Yu, Zhong, Lang, Liang, Lv, Xu and Tian. This is an open-access article distributed under the terms of the Creative Commons Attribution License (CC BY). The use, distribution or reproduction in other forums is permitted, provided the original author(s) and the copyright owner(s) are credited and that the original publication in this journal is cited, in accordance with accepted academic practice. No use, distribution or reproduction is permitted which does not comply with these terms. 


\section{GLOSSARY}

Akt protein kinase B

BeCSCs breast cancer stem-like cells

CAFs cancer-associated fibroblasts

CRC colorectal cancer

CREB cAMP-response element binding protein

ceRNA competitive endogenous RNA

EGFR epidermal growth factor receptor

ERK extracellular regulated protein kinases

EZH2 enhancer of zeste homolog two

FADD fas-associating protein with a novel death domain

GSK-3 $\beta$ glycogen synthase kinase $3 \beta$

HCC hepatocellular carcinoma

HP Helicobacter pylori

H19 long noncoding RNA H19

ICR imprinting control region

IGF2 insulin-like growth factor 2

lncRNA long ncRNA

IL interleukin

JAK the janus kinase
JNK $c$-jun n-terminal kinase

LPR lipoprotein receptor-related proteins

MAPK mitogen-activated protein kinase

MM multiple myeloma

MMP matrix metalloproteinases

mTOR mechanistic target of rapamycin

ncRNA noncoding RNA

NF-кB nuclear factor kappa B

NSCLC non-small cell lung cancer

PI3K phosphatidylinositol 3-kinase

PFTK1 cyclin-dependent kinase 14

RUNX1 runt domain transcription Factor 1

SOCS suppressors of cytokine signaling

STAT signal transducer and activator of the transcription

TCGA The Cancer Genome Atlas

TNBC triple-negative breast cancer

VGF neurosecretory protein

YWHAZ tyrosine 3-monooxygenase/tryptophan 5-monooxygenase activation protein zeta

ZEB1 zinc finger E-box-binding homeobox one 